\title{
An international cohort comparison of size effects on job growth
}

Michael Anyadike-Danes · Carl-Magnus

Bjuggren · Sandra Gottschalk • Werner Hölzl •

Dan Johansson · Mika Maliranta • Anja Myrann

the date of receipt and acceptance should be inserted later

Michael Anyadike-Danes

Aston Business School, UK E-mail: m.anyadike-danes@aston.ac.uk

Enterprise Research Centre, UK

Carl-Magnus Bjuggren

IFN, Sweden E-mail: Carl.Magnus.Bjuggren@ifn.se

Sandra Gottschalk

ZEW, Germany E-mail: Gottschalk@zew.de

Werner Hölzl

WIFO, Austria E-mail: Werner.Hoelzl@wifo.ac.at

Dan Johansson

HUI Research, Sweden E-mail: dan.johansson@hui.se

Örebro University, Sweden

Mika Maliranta

ETLA, Finland E-mail: Mika.Maliranta@etla.fi

University of Jyväskylä, Finland

Anja Myrann

Ragnar Frisch Centre for Economic Research, Norway E-mail: anjamyrann@gmail.com 
Abstract The contribution of different-sized businesses to job creation continues to attract policymakers' attention, however, it has recently been recognized that conclusions about size were confounded with the effect of age. We probe the role of size, controlling for age, by comparing the cohorts of firms born in 1998 over their first decade of life, using variation across half a dozen northern European countries Austria, Finland, Germany, Norway, Sweden, and the UK to pin down size effects. We find that a very small proportion of the smallest firms play a crucial role in accounting for cross-country differences in job growth. A closer analysis reveals that the initial size distribution and survival rates do not seem to explain job growth differences between countries, rather it is a small number of rapidly growing firms that are driving this result.

Keywords: birth cohort; firm age; firm size; firm survival; firm growth; distributed micro-data analysis

JEL codes: L25; L26; E24; M13 


\section{Introduction}

Much of the discussion of firm and job dynamics since the late 1970s has centred on contrasting the job creation performance of small and large firms. More recently, and following the analysis of newly constructed datasets, a consensus seems to be emerging that the age of firms may also be an important part of the story - age having been initially confounded with size because most firms are born small (Haltiwanger et al. (2013) henceforth "HJM")). However this 'consensus' does not yet extend to settled conclusions about small versus large (Neumark et al. (2011), Headd (2010)). Indeed this continues to be a very active area of research (see Ayyagari et al. (2014), Criscuolo et al. (2014), de Wit and de Kok (2014), Lawless (2014)).

The purpose of this study is to unravel the impact of firm size, survival and growth on overall job growth. We probe the role of size, controlling for age, by comparing the post-entry performance of cohorts of firms born in 1998 (cohort98) after their first decade of life, using variation across half a dozen northern European countries - Austria, Finland, Germany, Norway, Sweden, and the UK - to pin down the effects. There are three distinctive features of our approach: first, we use a purposebuilt dataset constructed by national experts using a commonly agreed measurement framework to make comparisons across countries; second, this allows us to use a finer grained treatment of small size than is usual - we divide firms with less than twenty employees into three size-bands; third, by analysing birth cohort data, we cut through many of the measurement-related complications produced by the potential confounding of age and size effects.

Cohort98 varies considerably across countries in a number of important ways. We develop a measurement framework which accounts for differences in job growth across countries due to differences in: 'initial conditions' - the average size of firms at birth by size-band, and the distribution of firms across size-bands; and 'transforming factors' - survival rates by size-band, and growth by size-band. The framework allows us to build on what is already known to be true of most countries,

- the bulk of firms - more than $80 \%$ in almost all cases - are born very small, into the smallest size-band we distinguish, with between 1 and 4 jobs

- smaller firms have lower survival rates than larger firms

- smaller firms record faster growth than larger firms

and show the extent to which these differences between countries account for differences in country-level job growth.

Firms' contribution to aggregate job growth is contingent on their survival and growth rates, which vary systematically with firm age and size. Previous research has had difficulties in disentangling these different effects. Our approach makes it possible to distinguish the effects of size, survival and growth while effectively controlling for age compared across countries. This allows us to uncover a key factor, contributing much of the variation in job growth across countries: the performance of the firms born into the smallest, less than five employee, size-band: the proportion of these firms that survive; the proportion that make a transition to the largest size-band; and the average job growth recorded by them during the transition. 
We find that:

- the very smallest firms in the cohort play a relatively large role in accounting for overall job growth

- a few rapidly growing small firms play a crucial role in accounting for crosscountry differences in job growth

- cross-country differences in the initial size distribution and survival rates contribute relatively little to the differences in job growth

Our findings have a significance which extends beyond the job creation "debate", they have implications for both theory and policy. Evidence on patterns of change by age and size are important for models of firm dynamics of the "selection and learning" variety, associated with Jovanovic (1982), Hopenhayn (1992) and Ericson and Pakes (1995). And, in respect of policy, as HJM observe, "... targeting firms based on size without taking account of the role of firm age are unlikely to have the desired impact on job creation." (Haltiwanger et al., 2013, p.360)

The analysis is conducted in three consecutive steps. First, we investigate the relative importance of different size categories, their survival and growth rates. Here we find that overall job growth is explained mainly by the contribution of the smallest and the largest firms. Second, we compare job growth between countries and observe that overall differences are explained by the growth rate of the smallest firms, and not mainly by the initial size distribution or survival rates. Third, based on the finding that the smallest firms were decisive for differences between countries, we investigate this size group in more detail. We find that the growth in this size band is driven by a very small number of rapidly growing firms. However, these firms are exceptional. We find in each country a very large proportion of the firms born very small, are still small after 10 years: their post entry performance cannot sensibly be characterised as "up-or-out" dynamics (as has become common), most surviving firms are neither "up" nor "out".

The rest of the paper proceeds as follows. In Section 2 we briefly review the literature, section 3 introduces the data and describes how it is put together whilst section 4 summarises some of its main characteristics. Section 5 introduces the primary decomposition and identifies the principal proximate determinants of job growth, whilst section 6 explores the key role of the smallest firms. Section 7 locates our contribution in the literature on job growth and section 8 sums up.

\section{Literature review}

This paper stands at the intersection of three separate (though not entirely distinct) literatures: it is a cross-country cohort study of job growth; and we will consider each of these three in turn. 


\section{1 cross-country comparisons of firm-level microdata}

In most countries the use of firm-level data for analytical purposes is relatively new, consequently the characteristics of the data are not always fully understood: in particular, much of it derives from information systems designed for administration rather than research and so definitions do not necessarily match at all well researchers' conceptual frameworks. Following from cross-country differences in administrative systems are cross-country differences in definitions and so some (often considerable) effort must be invested into trying to harmonise data before any meaningful cross-country comparisons can be made. ${ }^{1}$ We have adopted the approach pioneered by Bartelsman (with various collaborators) and referred to as "distributed micro-data analysis" (a term introduced in (Bartelsman et al., 2009, section 1.2)), where each country's data is prepared by local experts, thereby building in local knowledge of data sources, definitions and disclosure policies.

Over the last 20 years the number of countries for which firm-level datasets are compiled has increased markedly. Work making use of this data for cross-country studies is, however, still in its infancy. There are still not many more than a handful of studies using such datasets, amongst the most well-known are: Bartelsman et al. (2003) on firm demographics and survival; Bartelsman et al. (2009) on business dynamics (demography and productivity); Bartelsman et al. (2004) on creative destruction; and Haltiwanger et al. (2006) and Haltiwanger et al. (2010) on job creation and destruction. These studies (Bartelsman et al. (2003) excepted) feed into two distinguishable (though closely related) areas of research, one focuses on labour market dynamics, the other on productivity, but in both cases the key comparative concern is the association between cross-country differences in performance and cross-country differences in "institutions".

Until the recently published OECD-sponsored study Criscuolo et al. (2014) (which we discuss in some detail in section 7 below) there does not seem to have been much discussion of the connection between the size and age of firms, their survival, growth and contribution to job creation in cross-country comparisons built on harmonised datasets. For example, although two of the cross-country studies just cited discuss differences in survival rates by size at birth (see (Bartelsman et al., 2003, p. 25) and (Bartelsman et al., 2009, p. 53)) neither connect this discussion with the job creation records of different sized firms; whilst the discussion of job creation and destruction by size in Haltiwanger et al. (2006) and Haltiwanger et al. (2010) is not connected to variations in survival by size and age. ${ }^{2}$

\footnotetext{
1 For a, now slightly dated, summary of different cross-country datasets see Vale (2006)

2 Two other OECD studies make cross-country comparisons of (amongst other things) job creation and destruction: the first uses the Amadeus and Orbis databases and excludes firms with less than 20 employees, see (Bassanini and Marianna, 2009, pp. 33-35); the second, Schreyer (2000), was organised as a cross-country project involving researchers from six participating countries, the data was compiled from a range of administrative, public and private surveys, in most cases it excluded firms with less than 20 employees and considered only firms which survived the study period (between three and nine years, depending on the country). Moreover, as its "Methodological Annex" recorded: ".. major methodological differences remain and the present analysis is faced with the problem of harmonisation and consistency. The results obtained in each country are strongly marked by these differences." (Schreyer, 2000, p. 40)
} 
We compare data from six countries: Austria; Finland; Germany; Norway; Sweden; and the United Kingdom (UK). Bartelsman et al. (2009), which is closest to us in subject focus, compares many more, twenty-four in all (see (Bartelsman et al., 2009, Table 1.1, p. 25), but about half are transition or industrialising countries. There is some geographical overlap, but less than appears at first sight. The German data in Bartelsman et al. (2009) covers only West Germany and their UK data only manufacturing, indeed the only country in Bartelsman et al. (2009) with coverage similar to ours is Finland.

\section{2 cohort approach}

Since our central concern is firm and job dynamics by age, it seems natural to organise firm-level date into 'birth cohorts' which allows us, quite straightforwardly, to keep track of the size distribution of firms as the cohort matures. So rather than focusing on data averaged over a period of years, and treating the distribution of ages as a by-product, we will follow a cohort of firms from birth, using firm age to index the measurement of size, survival and growth. Using a cohort approach locates our study within the field of business demography or, to use the term suggested by van Wissen (2002), "demography of the firm".

A cohort approach is not very commonly applied to firm-level studies of size, survival and growth. However there is a strand of work which (since it investigated the post-entry performance of start-ups) has relied on the cohort as an organising principle, one notable exponent of this approach has been Kirchhoff, ${ }^{3}$ with Cabral and Mata (2003) a significant and rather better known example. ${ }^{4}$ More recently, the U.S. Bureau of Labor Statistics published a brief study of cohort98 using their new Business Employment Dynamics dataset Knaup and Piazza (2007), but without any size-band detail, whilst Stangler and Kedrosky (2010) have used the cohort approach, and stylised facts about survival by size, to simulate the evolution of the size distribution of firms.

Much of the cross-country analysis of firm dynamics in Bartelsman et al. (2009) makes use of period averages, however a cohort approach is deployed (necessarily) in the discussion of "post-entry performance" (Bartelsman et al., 2009, section 1.5.4). Indeed, one of their overall conclusions specifically recommends a cohort approach: "Measuring post-entry performance within countries appears to be somewhat more robust than the analysis of firm dynamics, since it implies following a cohort over time within a country." (Bartelsman et al., 2009, p.73). But their cohort-based study of post-entry performance did not discuss the connection between size and growth

\footnotetext{
3 see, for example: Kirchhoff (1994); Phillips and Kirchhoff (1989); and most recently Headd and Kirchhoff (2009).

4 Cabral and Mata (2003) compared a cohort of Portugese manufacturing firms at birth and age 7 to provide the empirical foundation for the suggestion that 'financial constraints' play a key role in the early growth performance of firms. However, of the many papers which cite Cabral and Mata (2003) and claim to be following their approach, relatively few have analysed cohort data.
} 
within countries, they considered the average size of all survivors across countries at three different ages. ${ }^{5}$

In brief, whilst it seems quite widely recognised that a cohort approachis a useful way to approach the study of business dynamics, ${ }^{6}$ cohort-based studies are still relatively rare, and cross-country cohort-based studies rarer still. Of course, in part this rarity indicates the difficulty in putting harmonised datasets together, but the case for our study design study has a deeper methodological justification. As we shall see, our cohort method enables us to uncover some deeper characteristics of firm and job dynamics and the comparison across countries then illustrates the importance of these characteristics in accounting for variations in cross-country job growth.

\section{3 job growth}

David Birch's 1979 report on the job generation process (Birch (1979)) - produced as part of a programme of work intended to inform policy on urban and regional regeneration - sparked a debate which has now continued (albeit somewhat intermittently) for more than thirty years. There were two novelties in Birch's report (subsequently updated and expanded in a book-length study, Birch (1987)): first, its use of firm-level records (compiled for the study from Dun and Bradstreet data); and second, the emphasis in its findings on what he claimed was the hitherto neglected contribution of small firms to job creation. ${ }^{7}$ Since one of the most recent contributions to the "job creation debate" has reviewed its history quite carefully ((Neumark et al., 2011, pp. 16-19)) and this account met with the approval of at least one of Birch's sternest critics (HJM), this history need not be rehearsed here.

The debate still continues although the issues and the methods used to address them have become considerably more refined. For example, in a new and authoritative contribution HJM draw a rather nuanced conclusion:

"We find some evidence in support of the popular perception that small businesses create most jobs ... If one looks at the simple relationship between firm size and net growth rates, there is evidence that net growth rates tend to be higher for smaller as opposed to larger businesses...

Our results show that the more important and robust finding is the role of firm age and its relationship with growth dynamics. We find that once we control for firm age, the negative relationship between firm size and net growth disappears ... Our findings suggest that it is particularly important to account for business startups." (Haltiwanger et al., 2013, p. 360)

\footnotetext{
5 They do, however, offer some somewhat speculative remarks about the contrast between US and European growth performance and its connection with size at birth ((Bartelsman et al., 2009, pp.53-57).

6 For example Haltiwanger at al draw the following methodological conclusion given the character of business dynamics, "Lumping together all firms of the same age is clearly misleading..."(Haltiwanger et al., 2009, p. 2)

7 Indeed, the subtitle of his 1987 book was:"how our smallest companies put the most people to work".
} 
HJM seems to be regarded as the 'standard' in the job growth literature, however not all recent studies share their conclusions, in some cases though (see Ayyagari et al. (2014) and Lawless (2014)) the datasets being analysed do not have universal coverage of the population of firms and, in particular, very small start-ups, which play such a key role, are very much under-represented.

Whilst we do address the "small versus large" question here - it is still a substantive, core, issue - we do so whilst taking particular account of the HJM argument and controlling for the effects of age. So our job growth question is a very precise one: what are the relative contributions to job growth after a decade by firms born into different size-bands? Moreover, in the course of answering this question we are able to show that the term "up-or-out dynamics" which leading papers in the field (Haltiwanger et al. (2009), Haltiwanger (2012), Haltiwanger et al. (2013), Decker et al. (2014), and Criscuolo et al. (2014)) regard as central to an understanding of the dynamism of the economy, obscures the significance of a small, but - in job growth terms - hugely influential, group of firms which are born very small but, by age 10, have more than 20 employees.

\section{Data and method}

As mentioned earlier, the data here has been produced by "distributed micro-data analysis", using local experts to build in local knowledge of data sources, definitions and disclosure policies but guided here by the measurement framework and definitions set out in the Manual of Business Demography EUROSTAT-OECD (2007).

The simplest way to proceed is to summarise the key dimensions of our 'benchmark' dataset and then list, in Table 1, the ways in which national datasets depart from it. The 'standard' is,

1. definition of a firm - an employer enterprise, that is a business with at least one employee

2. definition of employee - a person who receives a wage or salary from a firm

3. enumeration of employees - head count with no distinction between full-time and part-time employees

4. firm birth date - first employee joins

5. firm death date - last employee leaves

6. sectoral coverage - the 'private' or 'business' sector (NACE rev1.1: 15 to 74; 90 to 93)

7. enumeration of firms - all employer enterprises in the private sector

As may be inferred from this list, the choice of definitions is designed to be implemented using the administrative databases of a kind compiled by either, or both of, the tax authorities and the social security system. The strength of such databases is typically their universal coverage which follows from their role in administering the revenue and welfare systems. A common weakness, though, is that it is not always possible to distinguish between a de novo birth and firms which are 'born' following the break-up of an existing enterprise (or the parallel distinction between death and the sale of a firm), so we have not tried to make that distinction here. 
There is one important matter of measurement where we have not been able to harmonise the data entirely, the counting of jobs. In Austria, Germany, Norway, and the UK, we have a head count measure of jobs; in Finland the data is for "full time equivalents" (FTE); whilst in Sweden we count persons (each person has a single "main job"). ${ }^{8}$ Whilst these differences are obviously important, it is not clear that they will significantly affect the answer to our key question: the relative importance of the smallest firms to job growth (in fact, for Norway we have parallel datasets on all three bases, and some high-level summary statistics on these differences will be reported in the next section). Indeed the same criterion should be applied to other (perhaps as yet undetected) differences in national statistical practice: how might it affect our conclusions about the links between firm and job dynamics? ${ }^{9}$

Our study focuses on the cohort of firms born in 1998, measured at birth and then again a decade later in 2008. The key data analytical construct here is an 'origin/destination' (O/D) matrix whose 'origin' rows are four broad size-band categories at birth and whose 'destination' columns are size-band categories in 2008. Each country team was asked to provide three of these matrices,

1. an O/D matrix of firm counts: this is a $4 \times 5$ matrix, an extra column is needed for firms from each size-band which are 'dead' by 2008

2. an O/D matrix of employee counts in 1998: this is a $4 \times 5$ matrix, an extra column is needed for firms from each size-band which are 'dead' by 2008

3. an O/D matrix of employee counts in 2008: this is a $4 \times 4$ matrix, by definition only 2008 survivors are counted

Whilst this is quite a modest dataset, it nevertheless provides sufficient raw material to give some insight into how business dynamics and job growth vary across countries.

\section{Key facts}

\section{1 size of the cohort}

There is (unsurprisingly) considerable variation in the size at birth of cohort98 across our six countries, it varies by a factor of 16: from 240,000 in the UK to 13,000 in Norway (Table 2 panel (a) column (1)). Finland is closest in size to Norway, Germany is (relatively) close to the UK, while Austria and Sweden - at around 30 to 40,000 - are in between. If we scale the number of firms by (human) population size, as a crude adjustment for the size of an economy, countries look much more similar (Table 2, panel (a) column (5)). In five out of six there are between three and four cohort 98 businesses per thousand population, the only outlier is Germany where the figure is a little less than two, so the range of cross-country variation is reduced to about 2.25 .

\footnotetext{
8 This may also affect Sweden's firm count: firms in which every employee's main job is elsewhere would not be included.

9 For a discussion of the implications of measurement issues in harmonised cross-country datasets see (Bartelsman et al., 2009, pp. 27 - 32).
} 


\section{2 survival of firms}

It is well-known that a relatively large proportion of firms die young and although this is true of all countries, rates do vary internationally. In our case survival rates at age 10 from (Table 2, panel (a) column (4)) vary by a factor of about 2.5: in Sweden just $11.8 \%$ of cohort98 remains alive in 2008, whilst $30.7 \%$ survive in Austria. Most of the rest fall at one or other end of this spectrum, Germany and Norway record survival rates very similar to those in Austria, whilst the UK is closer to Sweden, only Finland sits mid way between the two 'groups'.

\section{3 number of cohort jobs}

The first three columns of Table 2 panel (b) record the jobs which correspond to the firm numbers displayed first three columns of panel (a): jobs at birth; jobs in 2008 survivors at birth; and jobs in 2008. The number of firms in the cohort varied across countries by a factor of 16 , but the number of jobs born into the cohort varies by considerably more: the number of cohort98 jobs at birth in the UK (1.12 million) is about 30 times the number of cohort 98 jobs at birth in Finland $(38,700)$.

Between birth and 2008 the number of cohort jobs shrinks dramatically, and the shrinkage is largely driven by the death of cohort members. For example, in the countries with the lowest survival rate - the UK and Sweden - jobs at birth in 2008 survivors are less than one fifth of all cohort jobs at birth (Table 2 panel (b) (column (2) $\div$ column (1))) - mortality over the decade cost Sweden more than 200,000 1998 jobs and the UK almost one million (Table 2 panel (b) column(4)). Substantial numbers of jobs are lost in the other countries too but, unsurprisingly, given the higher survival rates the proportion of jobs in the survivors at birth is rather higher, around two thirds.

\section{4 jobs per firm at birth}

The mean is not an ideal measure of central tendency for distributions as skewed as those of firm sizes, nonetheless the number of jobs per firm can provide a useable guide to the scale of inter-country differences. ${ }^{10}$ Finland records the smallest number of jobs per firm at birth (although this is certainly an under-estimate, since it is computed from full-time equivalent data) at 2.62 (Table 2 panel (c) column (1)), with Germany and Austria quite close by, both less than 3.5 and the UK around 4.5. Norway and Sweden are at the other end of the size distribution, with figures almost twice as large, more than seven jobs per firm at birth.

As mentioned earlier, we have 'person count' and FTE data for Norway, and the alternative measures based on these definitions have been included as a 'Memo' row to panel (c) of the table. You will see that - in the case of Norway at least counting persons instead of jobs makes very little difference to the results. The FTE measure makes more of a difference to jobs/firm, as might have been anticipated,

10 We will return to this issue later and look at the size distribution in a little more detail. 
average firms sizes are smaller. The growth ratio and average growth rates for the person count are very close to those based on the benchmark jobs definition, the FTE figures are lower, but not sufficiently to alter Norway's ranking.

\section{5 survival rates}

No more than $30 \%$ of cohort 98 firms survive the decade, and in some countries rather less. If we compute jobs per firm at birth of the 2008 survivors (Table 2 panel (c) column (2)), we find that - in every case - survivors are (on average) larger at birth than the birth cohort as a whole, and in the case of Finland, survivors are considerably larger (again, a likely side-effect of the full-time equivalent measure). This is evidence, at the aggregate level, of some size-related 'selection effect' - smaller firms die younger.

\section{6 growth}

The ratio of jobs per firm in 2008 to jobs per firm in survivors at birth (Table 2 panel (c) column (3)) provides a measure of the growth in the number of jobs since, by definition, the denominator of jobs per firm, the number of 2008 survivors is fixed. ${ }^{11}$ The UK recorded a doubling of jobs per firm, the strongest growth in jobs per firm, and by implication in overall jobs, since number of surviving firms is given. The UK is followed closely by Finland, then Germany and Austria with each of the latter two recording about $80 \%$ growth over the decade. Norway and Sweden ${ }^{12}$ posted more modest gains of $50 \%$ and $33 \%$ respectively. The final column of panel (c) translates job growth into a more conventional measure, the annual average growth rate over the decade. Notice that even the slowest growing country, Sweden, records a 'respectable' $3 \%$ per annum, whilst at the top end of the scale the UK figure at $7.5 \%$ is more than twice as large (and Finland is close by at $7.3 \%$ ).

\section{Digging below the surface: decomposing job growth}

Both firm survival and growth vary systematically with age and size, but we condition on age by using cohort data to expose the extent and nature of the connection between cross-country variation in size-specific firm survival and growth rates and cross-country variation in overall jobs growth. Here we use just four size-bands to capture the size-specific character of survival and growth effects, measured in terms of employee numbers they are: 1 to $4 ; 5$ to $9 ; 10$ to 19 ; and $20+$.

\footnotetext{
11 An alternative measure of growth over the decade would be the ratio of jobs in 2008 to jobs in all firms in 1998, but this measure confounds survival and growth, which we keep separate here. In any event, the ordering on the alternative growth measure is rather similar.

12 It might be conjectured that Sweden's relatively slow growth might be connected to the different measure of employees. Of course, it is not possibly to know, however, to make such a difference to the growth calculation would require not just multiple job holding but increased multiple job holding in cohort 98 over the decade.
} 
Whilst summarising a firm size distribution in just four categories might, a priori, appear to be an oversimplification, as we shall see, the only (empirically) plausible alternatives would have involved slicing the size-bands even more finely at the small end. ${ }^{13}$ In any event, in practice, this size-band classification pinpoints quite effectively the similarities and differences between countries, and allows us to uncover the impact of size on the pattern of job growth.

We make use of an expression which represents overall growth in jobs per firm as a weighted sum of the size-specific growth rates of firms. The 'weights' in this sum of the size-band specific growth rates can be expressed in terms of five factors which, when combined, connect firms in the cohort at birth to all those which survive. These five components fall into two groups. The first two are initial conditions,

- the average size at birth in each size-band $\left(\operatorname{avjob}_{i}^{b}\right)$

- the share of each firm size-band at birth $\left(\right.$ firmsh $\left._{i}^{b}\right)$

and the other three capture the transforming effects of survival and growth. Since the two relative survival ratios may be less familiar they are explained in more detail,

- within size-band relative survival effects $\left(r s r w_{i}\right)$ : this ratio operates on the average job by size-band figure, and it is a variety of 'selection' effect which arises because we use size-bands rather than single sizes, and survival rates vary by size inside the size-band. So, for example, differential survival ratios by size within size-band 1- 4 (where, say, survival ratios for firms size 1 are lower for firms born size 1 for firms born size 2, etc) will produce an average jobs per firm figure for surviving firms in the size-band $1-4$ larger than for the firms in the size-band $1-4$ at birth. This survival ratio is computed, size-band by size-band, as the ratio between the average jobs per firm in surviving firms at birth in a size-band $\left(a v j o b_{i}^{b s}\right)$ and the average size of all firms at birth in that size-band $\left(\operatorname{avjob}_{i}^{b}\right)$

- between size-band relative survival ratio $\left(r s r b_{i}\right)$ : this ratio operates on the firm share (size) distribution, it captures the fact that different size-bands have different survival ratios, typically larger size-bands have higher survival ratios than smaller size-bands. This term, another size-related 'selection' effect, is computed, size-band by size-band, as the ratio between the average survival ratio for firms in a size-band and the average survival ratio for all firms

- size-band specific growth rates $\left(\right.$ growth $\left._{i}\right)$

where the $i$ subscript denotes the size-band.

The relationship between these factors and overall growth is set out formally in equation $(1)^{14}$,

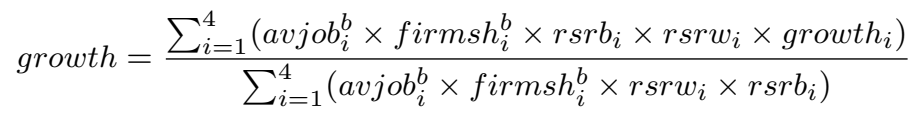

Table 1 provides some intuition about the logic of this relationship. It is a graphic

\footnotetext{
13 Moreover, in smaller countries, with relatively few firms born very large, the statistical authorities do not permit publication of data which might allow individual firms to be identified.

14 Precise definitions and a derivation are provided in the Appendix section A.1.
} 
which displays the way the factors combine. Across the table we represent the effects of survival and growth on firm performance, affecting average jobs/firm and the firm size distribution. As explained above, because survival rates depend on size, both 'initial conditions' - average jobs per firm at birth and the firm size distribution at birth - are scaled by a relative survival ratio. Both of these represent different varieties of selection effect: a within size-band relative survival ratio (in the first row) because the average size of survivors within a size-band may differ from the average size at birth; a between between size-band relative size band ratio (in the second row) because survival rates may differ by size-band. So the middle ('survivors') column records the average jobs per firm for survivors at birth and the firm size distribution of survivors at birth. Multiplying the average jobs/firm of survivors at birth by size-band specific growth rates (in the 'growth' column) yields the average jobs/firm in the terminal year. Down the table we represent the combination of jobs/firm by size-band and the firm size distribution into weighted components which sum to the aggregate job/firm figures and from which, ultimately, the measure of overall job growth can be computed.

\section{1 a tour of the decomposition}

Rather than start with the specifics of each of the national datasets, we use data from one country - Austria ${ }^{15}$ - to introduce and illustrate the decomposition. Not only is Austria towards the 'middle' of the growth rate distribution, it turns out to have 'middling' values for most components of the decomposition. The Austrian data on the components of the decomposition is displayed in Table $4^{16}$, which is laid out using the same 'matrix' display as was used to illustrate the relationship between the concepts in Table 3 .

The cohort at birth is described in the first column. The first block of four rows is average jobs/firm. Since the first three size-bands are bounded we already know the range within which the average jobs per firm will fall, what we can see though is that, in each case, the size-band average is below the mid-point of the size-band. This suggests there is some skew in each distribution towards the bottom of its range. The largest size-band is unbounded and there the average size is almost 70 employees per firm. In the next block we have the firm share distribution, and its principal feature is the extraordinary concentration in the smallest size-band - 89\% of all firms have less than five employees. Only 6\% are in the $5-9$ size- band, with the rest shared almost equally by the other two. From the third block going down the column - the weighted average terms - it is immediately apparent that the contributions to the overall jobs/firm at birth reflect the balance between the very large number of very small and the very small number of the very large. In fact, the weighted contributions of the $1-4$ size-band and that of $20+$ size-band are

\footnotetext{
15 Austria was chosen after some experimentation with alternative approaches to constructing a cross-country 'average'.

16 A more detailed treatment of the Austrian decomposition is laid out in the Appendix A.2 and its accompanying table. It displays the size-band detail which evidences some of the comments in the text about the relative importance of different effects.
} 
both about $40 \%$. So the average size at birth -3.40 jobs per firm - is (proximately and largely) determined by the two ends of the distribution.

As we know the effect of death flows through different channels: it alters the average size within each size-band; and it changes the balance between the size-bands. The first effect is recorded in the first block in the 'survival' column and is, in most cases, relatively small. The only impact much larger than $1 \%$ is in the smallest sizeband, where average size increases by about $12 \%$, although the resulting average size at birth (in the 'survivors' column) at 1.72, is still well below the mid-point of the distribution. By contrast, the $20+$ jobs per firm figure, at 67.42 , is virtually unchanged. The effects of death on the firm share distribution recorded in the second block are, by contrast, quite substantial. Although the shrinkage at the small end (about $5 \%$ off the $1-4$ share) is quite modest, there is a huge (proportionate) expansion at the larger end (in each case by more than $40 \%$ ). Nonetheless, as you will notice from the firm size distribution of survivors (the second block in the survivors column), and notwithstanding the size of the relative survival rate effects, the share of $20+$ firms is still just about 3\%. Looking further down the 'survivor column to the next block, we see that the balance in the weighted contributions has shifted quite noticeably, and the $1-4$ contribution now rather smaller than the $20+$ share. The resulting average job figure, at 4.52 , is one third larger than the comparable figure at birth: clearly the size-related selection effect on the firm size distribution has had quite a substantial impact.

In the 'growth' column we have the effects of differences in size-band specific growth ratios. ${ }^{17}$ The gradient in the size-band effect is the most obvious feature: the growth ratio for the $1-4$ size-band is almost twice that of the $20+$ size-band. Even the two larger size bands show around 50\% more growth than does $20+$. In the 'terminal' column we see the significance of the size differential in growth. After ten years the average jobs/firm exceeds the upper bound for each of the bounded size-bands, whilst the largest firms are (on average) not very much larger. When weighted by the firm share distribution (which is, of course, that of the survivors at birth), we see that the weighted contributions have shifted quite strikingly towards the small end of the distribution: the smallest firms, by age ten, contribute almost half the cohort average, whilst the contribution of the 20+ group, is now less than one third. The pattern of contributions now looks quite different to either the whole cohort at birth or the survivors at birth. The distribution is still bi-modal - a large share of size-band 1-4 firms, a small share of 20+ firms - but the contribution of the smallest firms is very considerably more important. As we shall very soon see, it is a small but significant group of the survivors from the $1-4$ size-band, having out-grown their size-band at birth, which are driving this finding.

The 2008 figure for average jobs per firm is 7.73, 70\% larger than the corresponding figure for survivors at birth, equivalent to annual average job growth of $5.5 \%$ over the cohorts first decade of life. Figure 1 serves as a graphical summary of the role of the three transforming factors in this outcome. The data have been plotted on a log scale to make them more readily comparable (since they enter the relation-

\footnotetext{
17 Remember growth is being measured here as the ratio between average jobs per firm in survivors at birth and in the terminal period, ten years later.
} 
ships multiplicatively). The display provides visual confirmation of what is generally known: survival prospects are better for larger firms; and post-entry growth performance is stronger for smaller firms. We will now examine how their relative importance contributes to cross-country job growth.

\section{2 cross-country variation and the decomposition}

Quite some time has been devoted to the Austrian data, using it to introduce the components of the decomposition. Now we will investigate the extent to which other countries depart from the Austrian 'average' and which of these departures play the most important role in accounting for the differences in job growth which, as we saw earlier, varies markedly with the UK growing $30 \%$ faster than Austria, and Sweden $50 \%$ slower.

Using Austrian data as the baseline we have constructed Table 5. It records the difference between a country growth ratio and that of Austria as the sum of the differences between that country and Austria, component by component. It is constructed by replacing each of the elements of the Austrian decomposition, one at a time, and recording the difference from the Austrian growth ratio. These elements are the two initial conditions: average number of jobs per firm at birth $\left(a v j o b^{b}\right)$; the firm size distribution at birth $\left(\right.$ firmsh $\left.^{b}\right)$; and the three transforming factors: the two selection effects, the 'between' relative survival ratio $(r s r b)$ and the 'within' relative survival ratio (rsrw); and the growth ratio (growth).

If all the components of the decomposition were additively related the sum of these individual differences for a country would exactly equal its overall difference from Austria, but of course we know the relationship is not additive. In particular, within a size-band, the elements are combined multiplicatively, so there may be a discrepancy between the sum of the 'marginal' effects of each component and the country's growth ratio. We refer to this discrepancy as an 'interaction effect' and it is recorded in column (6) of the table. The data on the components of the decomposition for all countries used in the construction of Table 5 and the (other) analytical tables is provided in an Appendix.

As noted earlier, three of our four size-bands are bounded ${ }^{18}$ so the pattern of contributions in column (1) reflects, almost entirely, the negative association between overall growth and the average size of firms in the 20+ size-band. The negative differences for UK, Finland and Norway indicate that, for them, the average size of the 20+ firms exceeds that of Austria, whilst the average size of 20+ firms in Germany is rather smaller. Notice that there is only a weak association between these differences and the growth rate ranking.

We see straight away from column (2) of Table 5 that Germany's firm share distribution at birth is essentially the same as Austria's. However, the two countries lower

\footnotetext{
18 With the partial exception of Finland where the job numbers are full-time equivalents and so some firms in the $1-4$ size-band have, in practice, less than one job.
} 
down the growth rate distribution than Austria - Norway and Sweden - record sizeable negative differences, whilst for Finland and the UK, the two countries higher up the growth rate distribution, the differences are positive. What differentiates these two pairs of countries is that the UK and Finland have a larger share of firms (than Austria) in the 1-4 size-band - positively associated with growth and a smaller share of firms (than Austria) in the 20+ size-band - negatively associated with growth; whilst for Norway and Sweden (relative to Austria) the position is reversed. Simplifying, the firm size distribution in the UK and Finland is more positively skewed than in Austria, whilst in Norway and Sweden it is more negatively skewed.

We can also see from columns (2) and (3) of the table that differences in relative survival rates play almost no role in accounting for job growth differences. By implication, most countries have survival rate curves which resemble quite closely those for Austria depicted in Figure 1. The only substantial figures are for Finland, and again these are likely a by-product of the full-time equivalent effect since the firms with very smallest number of employees seem most prone to die.

Finally we come to the growth terms. These produce most of the more sizeable contributions (both positive and negative) to the growth rate differences, so it is worth examining them in some detail. The UK and Finland record the largest positive contributions from size-band specific growth and Figure 2, which displays the growth ratio data for all six countries, helps us understand why: the UK and Finland both have more rapid growth than Austria in every size-band (although the difference in $20+$ is very small). The largest negative contribution is recorded by Sweden where growth in the $1-4$ size-band is extraordinarily modest, and much lower than Austria. Germany's growth most closely resembles the UK and Finland at the small end of the size distribution, but the relatively rapid growth of the smallest firms is not sufficient to offset very much slower growth elsewhere (and indeed the contraction of jobs in the $20+$ size-band), so for Germany overall the contribution is negative.

One feature of Figure 2 - the 'big picture' - that stands out is that, for most countries, size and growth are negatively related, though by no means monotonically. Since the data has (again) been plotted on a log scale, the inter-size-band differences between datapoints within a country can be interpreted as additive contributions to the overall country growth.

\section{Job growth under the microscope}

We have seen that size-band specific job growth typically plays a larger role than the firm size distribution, average size at birth, or survival rates in accounting for relative growth performance. We know too that growth rates vary by size-band, and that - comparing size-bands - smaller firms typically grow faster than do the larger. It is possible to perform a more focused decomposition to tease out the relative importance of each size-band specific growth rate, and here again we use Austria as the benchmark. Country by country, we replace each of the size-band specific growth rates one at a time. The results of this exercise are recorded in Table 6. In 
every country the growth rate of the $1-4$ size-band produces the contribution to the overall growth rate with the largest absolute value. ${ }^{19}$ By extension, then, it is growth rate differences between the $1-4$ size-band across countries which account for the bulk of the overall variation in job growth between countries. Indeed, only in Germany, where 20+ firms actually contracted, does any other size-band play a substantial role.

6.1 decomposing the growth rate contribution of the smallest firms: Austria

Let us now drill a little deeper. Not all firms born in size-band $1-4$ remain there: in the case of Austria we know from Table 4 that the 2008 average size of firms born 1 -4 firms fell just outside the size-band. So 2.341 is the growth ratio of all firms born in the size-band $1-4$, and is a weighted average of the growth ratios of some firms which remain in size-band 1- 4 and others which are now in a larger size-band. ${ }^{20}$ The first row of Table 7 records Austrian data on the growth ratio of firms born in size-band $1-4$ classified by their 2008 size-band. The dispersion around the sizeband 1- 4 average of 2.341 is considerable: firms which remained in size-band $1-4$ recorded half the average growth at 1.13; whilst firms which made the transition to $20+$ reported ten times the average.

It turns out to be quite straightforward to uncover the effects of transitions by firms born $1-4$ by decomposing the $1-4$ growth ratio according to the size-band in 2008 . This decomposition involves three size-band specific ratios,

- the first, we have just seen, is the size-band specific growth ratios, one for each of the four 'destination' size-bands $\left(g r_{i}\right)$

- second, we have a 'selection' adjustment, which captures the fact that the average size of $1-4$ firms at birth varies slightly across their 'destination' size-bands - those which move into larger size-bands turn out to have been slightly larger at birth $\left(\right.$ sel $\left._{i}\right)$

- finally, a 'mobility ratio', the proportion of firms born in size-band 1 - 4 which are in each 'destination' size-band in $2008\left(m o b_{i}\right)$

These three terms are not necessarily related: faster average growth of these firms need not imply a larger mobility ratio, nor would a larger mobility ratio necessarily imply faster average growth (see below the cases of Germany and Norway).

We can represent jobs growth in the 1-4 size-band as the sum over all four 'destination' size-bands (so including 1-4 as a destination for those firms who finish in 1-4) of the product of these three terms,

$$
\frac{a v j o b^{t}}{a v j o b^{b}}=\sum_{i=1}^{4}\left(g r_{i} \times s e l_{i} \times m o b_{i}\right)
$$

\footnotetext{
19 In Germany, as we saw from Figure 2, 20+ firms contracted and this produces a negative contribution of equal absolute value to size-band $1-4$ growth.

20 Our data does not allow us to infer whether these firms remained in the same size-band throughout the decade: they may have moved out and moved back, though a priori this does not seem very likely to be a widespread phenomenon.
} 
The growth ratio for all firms born in size-band $1-4$ is the sum over all size-bands of these contributions. The data corresponding to the components and their contributions are set out in the rows of Table 7. A formal derivation of this decomposition is provided in the Appendix, section A.2.

We have already looked at the growth row in the table, and by contrast the selection adjustment in the second row is relatively small and hardly varies. Essentially, firms which grow out of the $1-4$ size-band are about one third larger than the birth sizeband average (that is 2.3 rather than 1.72 ), while those which remain are about $8 \%$ smaller (1.58 rather than 1.72). The mobility ratio is quite small too, but, importantly, it varies considerably across the row $-80 \%$ of size-band $1-4$ firms remain $1-4,2.2 \%$ grow into the $20+$ size-band - the proportion remaining is larger by a factor of 36 than the proportion becoming $20+$.

Overall then we have a set of contributions, recorded in the bottom row, which are bi-modal: a large proportion of relatively slow growing firms which remain in sizeband $1-4$, and a very small proportion of relatively fast growing firms which move into the 20+ size-band. From the shares, recorded in the last row, we see that these two largest contributions account for about two thirds of the overall size-band 1-4 growth ratio. Whilst it may be, as we saw in the previous section, that it is sizeband $1-4$ growth which drives the overall rate of job growth, it is now clear that in Austria it involves just $20 \%$ of the 2008 survivors, and that much of it is contributed by the $2.2 \%$ which grew to have more than 20 jobs.

6.2 decomposing the growth rate contribution of the smallest firms: using an Austrian baseline

We now perform a final exercise in decomposition to determine which of the three factors - growth, adjustment and mobility - plays the largest role in the variation across countries in the growth of firms born in size-band $1-4$, again measured as differences from Austria. Table 8 records the results of the contributions to growth of the three ratios (together with a residual 'interaction' effect). First, it is worth noticing that the ranking of $1-4$ job growth (column (5) of the Table) is the same as the ranking on overall job growth. Unsurprisingly the 'selection' effects are no more important across countries than they were for Austria. The mobility effect is relatively large in most countries, and in all the four countries which recorded more growth in size-band $1-4$ than Austria its contribution is positive. However, in Sweden, which recorded lower growth than Austria, the mobility effect is large and negative: a smaller proportion of firms leave the $1-4$ size-band. The contributions of the growth rate effect are more variable. It plays an important and positive role in the UK and Finland, and an equally important and negative role in Sweden, but it contributes relatively little to accounting for the cross country growth differential in Germany or Norway.

The overall conclusion here is that a greater degree of mobility - a relatively large proportion of firms leaving their size-band at birth - seems to be necessary, but not sufficient, for faster job growth. The strongest performance is recorded in those 
countries where mobility is accompanied by relatively rapid growth. ${ }^{21}$ It is also worth noticing that in all countries, most of this (potentially) crucial group of very small firms do not leave their birth size-band, in every case $70 \%$ or more of those that survive (typically around $90 \%$ to $95 \%$ of the all firm average) after a decade still record no more than four jobs.

\section{Locating our results and extending the evidence base}

As we saw earlier the role of firm size in job creation and destruction remains controversial. If we are to build an evidence base in this area it is necessary to be clear about how results from the different studies fit together. Here we take the influential (and highly cited) ${ }^{22}$ HJM study as the 'benchmark' and set out how our key results, derived using an entirely different methodology, 'fit' within their framework. The first key element of their findings is, of course, the age/size result,

"First, ... when we do not control for firm age, we find an inverse relationship between net growth rates and firm size ... Second, once we add controls for firm age, we find no systematic inverse relationship between net growth rates and firm size. A key role for firm age is associated with firm births. We find that firm births contribute substantially to both gross and net job creation." (Haltiwanger et al., 2013, pp. 347-348) ${ }^{23}$

So how does our answer to: "who creates jobs?" differ from HJM? We need first to outline their methodology before we can explain.

".. we use a nonparametric regression approach to quantify these relationships...In our main specification, we regress net employment growth and its components at the firm level on firm size classes by themselves, on firm age classes by themselves, and by firm size and age interacted together. The latter specification follows naturally from [our] tabulations ... which show net growth patterns for firm size and firm age cells. All of the empirical models we consider are fully saturated dummy variable models."(Haltiwanger et al., 2013, p. 354) $)^{24}$

We can represent our data in 'HJM format' as a matrix with rows representing firm ages and columns representing firm size-bands at birth, with each cell in the matrix recording a job growth measure. In our case the job growth is measured over a ten year period, 1998 to 2008 . So, for example, our data for each country would

\footnotetext{
21 In Norway, for example, with the greatest mobility, much of the movement out of the birth size-band, much more than in other countries is into the 5-9 and $10-19$ size-bands, see Appendix for details.

22 The influence of HJM is very noticeable in three out of the four 2014 papers we cited earlier, that is Ayyagari et al. (2014), Criscuolo et al. (2014), Lawless (2014) discuss HJM; oddly de Wit and de Kok (2014) does not, perhaps because it ignores the significance of age altogether.

23 They also add a generlaisation which must be regarded as a conjecture since they provide no specific evidence: "Importantly, because new firms tend to be small, the finding of a systematic inverse relationship between firm size and net growth rates in prior analyses is entirely attributable to most new firms being classified in small size classes." (Haltiwanger et al., 2013, p. 348)

24 The approach adopted by HJM had previously been applied to similar problems: see Evans (1987) and Dunne et al. (1989)
} 
contribute to one row: job growth for survivors aged 10 (continuing firms in HJM terms). The cells in this row in the case of Austria, for example, would be the cells in the 'growth' column of Table 4 . The next row in the matrix would be a the observations for age 11, a ten year growth of cohort98 survivors from 1999 to 2009, age 12 for the next row, and so on. The next step in a 'HJM-style ' analysis would be to fit a line to the job growth by size-band for all six countries ( i.e. to the data plotted on Figure 2) and enter the coefficients from that fit as the entries corresponding to age 10 in the same way that HJM average by size-band coefficients over years by age. Instead, we have simply plotted the cross-country average on Figure 1, and you will see that there is an inverse relationship between size and growth. So we can confirm that our evidence on job growth by size-band at birth - for 10 year growth in a single age-band by size-band at birth - is consistent with HJM's conclusions about the relationship without age controls. ${ }^{25}$

Although we have not produced results which correspond to HJM's case 'with age controls', an informal argument turns out to be sufficient. Consider an alternative to our first data matrix, where the rows are still ages but the columns are now sizebands for firms at age 10 (the terminal year of our growth period), which substitute for birth size-bands. ${ }^{26}$ So the cell in the $1-4$ column would average the growth record of firms born $1-4$ which remained $1-4$ and that of firms born in other (larger) size-bands but which had by age 10 shrunk into the $1-4$ size-band. Some of the born $1-4$ firms might have grown (but at most from 1 to 4 - the bottom to the top of the size-band), so the overall $1-4$ average growth is more or less guaranteed, by construction, to be relatively slow. A similar argument can be applied to the other size-bands. However, the average would be a mixture of three groups of firms: those which remained in their birth size-band; those which have 'moved up' and grown into a larger size-band; and those from larger birth size-bands that had 'moved down'. In summary, it seems likely, a priori, that growth in the $1-4$ sizeband 'with age controls' would be lower than that in the larger size-bands. Whilst the overall shape of the relationship cannot be predicted, the inverse association between growth and size seems very likely to disappear. In our case, we can confirm (though the evidence is not presented here) that it is consistent with HJM's findings about the relationship with age controls.

As our informal argument has revealed, though, the HJM findings about the likely shape of the age/size relationship with age controls can be written in terms familiar from our discussion of the contribution to job growth of the smallest firms (in section 6.2). In brief, growth by size-band for continuing firms with age controls can be decomposed into three terms: 'growth', the size-band specific growth rate; 'selection', the average growth within the size-band; and 'mobility', the proportion of firms moving from one size-band to another. Indeed we showed earlier that differences in growth and mobility of the smallest firms were associated with crosscountry variation in overall job growth. There we were focused on just the smallest size-band, but of course the same approach could be applied to the other size-bands as well.

25 Although the 'slope' of the relationship is pretty flat between size $5-9$ and size $10-19$.

${ }^{26}$ HJM actually use 'average' size rather than terminal size, but this is not crucial here. 
The decomposition into these three terms also helps to provide some important context to HJM's second finding, the characterisation of start-up firm dynamics, the second of HJM's main findings, on the critical role of start-ups,

"Our findings emphasize the critical role start-ups play in U.S. employment growth dynamics. We document a rich up-or-out dynamic of young firms in the United States. That is, conditional on survival, young firms grow more rapidly than their more mature counterparts. However, young firms have a much higher likelihood of exit, so job destruction from exit is also disproportionately high among them."(Haltiwanger et al., 2013, p.348)

What light do our results shed on the characterisation of start-up performance as "up-or-out dynamics"? Certainly, as we have shown, a very large proportion of the cohort in each country is "out" after ten years (survival ratios range from $10 \%$ to $30 \%$ ). However, it is less clear that "up" usefully describes the average behaviour of those that do survive to age 10. The term 'up' in this context can be translated directly into what we call 'mobility'. Although we have only presented evidence here on the very smallest firms, because of their preponderance in the population (between $60 \%$ and $80 \%$ of survivors in the $1-4$ size-band at birth ${ }^{27}$ ) they exert a very considerable influence. Now from Appendix Table 3 we can see that between $69 \%$ (Norway) and 93\% (UK) of firms have not moved 'up' - at age 10 they are still in the $1-4$ size-band in which they are born. So the bulk of firms in any cohort that survive 10 years hardly grow at all. Moreover our finding, which is apparently entirely contrary to the HJM claim, has rather wider significance since as noted earlier it is argued that the "up-or-out" dynamic is consistent with predictions in formal models of firms which stress market selection and learning. The dynamic we observe is better characterised by "not-up-nor-out" dynamics and this is not (in any obvious way) consistent with those models.

Interestingly, similar views on this issue have been expressed in a recent paper (based on U.S. data) by Hurst and Pugsley (2011). On the empirics they conclude,

"Haltiwanger, Jarmin, and Miranda (2010) [published as 2013] show that, when one controls for firm age, there is no systematic relationship between firm size and growth. They conclude that those small firms that tend to grow fast (relative to large firms) are newly established firms. We discuss in later sections how our results add to these findings. In particular, we show that most surviving new firms also do not grow in any meaningful way." (Hurst and Pugsley, 2011, p. 74, n.1)

Moreover, Hurst and Pugsley (2011) go on to draw the same inference as we have done about the inadequacy of the 'standard models' in accounting for the heterogeneity in firm post-entry performance.

In a more recent paper, HJM (with an additional co-author), recognise more explicitly the heterogeneity in the growth performance of young firms,

"Most business startups exit within their first ten years, and most surviving young businesses do not grow but remain small. However, a small fraction

\footnotetext{
27 This figure can be calculated from Appendix Table 1 as the product of firmshb (column (2) and $\operatorname{rsrb}$ (column(3)).
} 
of young firms exhibit very high growth and contribute substantially to job creation. These high-growth firms make up for nearly all the job losses associated with shrinking and exiting firms within their cohort." (Decker et al., 2014, p. 4)

But having observed that only "a small fraction" record very high growth, this finding, somewhat oddly, is still characterised as "up-or-out" dynamics. It appears then that HJM now recognise the importance of what they refer to as "high-growth firms" in the U.S. ${ }^{28}$ most of which will be accounted for by the small group of firms which we have demonstrated play a key role in differentiating the job growth in the six European countries we have studied.

It is also worth considering the findings reported in the recent OECD-sponsored study Criscuolo et al. (2014) with ours. They too make use of an internationally harmonized firm-level dataset (in their case for 18 countries and three year growth periods) where the data is prepared and processed (by size-band, age-band and broad sector) by country experts. The cross-country analysis and commentary is provided by OECD officials. Their results on the age-size relationship seem broadly in line with HJM (and so ours). They also share with HJM the same 'tension' in relation to "up-or-out" dynamics: on the one hand they point to the large proportion of start-ups surviving three years which did not grow; but on the other hand they still use the term "up-or-out dynamics" to describe post-entry performance (see (Criscuolo et al., 2014, pp. 30-36)).

What most clearly differentiates our paper from the OECD work, though, is the use of a decomposition to investigate the contribution of different factors to international differences in job growth. So, for example, they discuss the firm size distribution, the average size of startups, and so on (see (Criscuolo et al., 2014, section 3)). But, without a framework which connects those factors in a systematic way, they are not able to determine the 'weight' to be given, for example, to differences in the proportion of small firms in accounting for cross-country differences in job growth.

\section{Summing up}

Following a cohort of firms over time using a unique cross country dataset, we find that a very small proportion of the smallest firms play a crucial role in accounting for cross-country differences in job growth. By using a purpose built dataset we are able to get a finer grained treatment of small size than is usual, and the cohort approach cuts through many of the measurement-related complications produced by the potential confounding of age and size effects.

We analyse the variations in job growth in three consecutive steps. First, we use Austria as a benchmark to investigate the relative importance of different size categories, their survival and growth rates. We find that overall job growth is explained

\footnotetext{
28 Whilst Decker et al. (2014) use the term "high-growth" this is not the conventional (OECD) usage (see Anyadike-Danes et al. (2012) for discussion of the high growth firm definition and its application); indeed, in this context, young and very fast growing, they could be referring to "gazelles", though not as conventionally defined, see Henrekson and Johansson (2010).
} 
mainly by the contribution of the smallest size-band (1-4) and the largest (20+). Second, we compare the other five countries with Austria and find that the overall difference in job growth between countries is explained by the smallest size band (1-4). Moreover, the differences between countries are due to different growth rates rather than different rates of survival or the initial size distribution of firms. Third, based on the finding that the size-band (1-4) was decisive for differences across countries we decided to investigate this group of firms in more detail. We find that the growth in this size band is driven by a very small number of rapidly growing firms.

The analysis of job creation using data on birth cohorts of firms is quite rare, the international comparison of birth cohorts is rarer still. We have adopted this approach for two reasons. First, the perennial argument about the role of firm size in generating job growth has been complicated, it is now appreciated, by the confounding effects of age because most young firms are small. By observing a cohort of firms at birth in 1998 and at age ten in 2008, we can compute job growth comparisons for firms across size-bands which are, by construction, uncontaminated by the effect of differences in age. Second, applying the same method to datasets for a number of countries - Austria, Finland, Germany, Norway, Sweden, and the UK - which recorded quite widely varying rates of job growth over the decade 1998 to 2008, helps to provide a clearer perspective on the relative importance of size. Third, the cohort approach makes it possible to unravel the impact of survival and growth on overall job growth. It is important to be clear, though, that our findings about size reported here refer to size at birth. Of course, this is not an inherent feature of cohort-based comparisons: we could have made a ten year comparison between the cohort at five and at age 15. What is inherent to the cohort approach is an intuitive and effective means of disentangling age and size effects which does not rely on an indirect accounting for the (possibly non-linear) effects of age as is required when comparing cross-sections of firms of mixed age at two different points of time.

Although the data used in this study is novel, there are some limitations which should be noted - only six countries, a single cohort, one point to point comparison over time - which suggest immediately directions in which it might be generalised. There are now many more countries which compile the necessary data, for most of the countries covered by this study at least two more cohorts (up to age ten) are already available, and of course it would be interesting to follow job growth (and the contributory dynamics of selection and survival) year by year. Of course, data of the kind analysed here - especially the annual time series version - could provide a much deeper insight into the dynamics of employment change. It could, for example, help to extend and enrich the conventional job creation and destruction accounts by tracking the movement of expansion, contraction and exit by age.

The cross-country cohort design employed here adds to the body of evidence on post-entry firm performance and job growth. First, it confirms some widespread perceptions about newly born firms: they are typically very small, more than threequarters in each of our six countries have less than five employees; relatively few survive ten years (and fewer still of the smallest); but the firms born smallest which survive grow faster. Our findings are consistent with the well-known HJM results: 
that job growth is inversely related to firm size, and that adding controls for age causes this relationship to disappear.

We do however disagree with HJM that post-entry firm performance can sensibly be characterised as "up-or-out" dynamics. Indeed, quite the contrary, we find in each country a very large proportion of the firms born very small, are still small after 10 years: they are neither "up" nor "out". Moreover we have also drawn attention to the fact that a very small group of the smallest firms make a disproportionate contribution to job growth, and that the relative importance of these firms and the variations in their pace of growth make an important contribution to accounting for cross-country differences in overall job growth.

More broadly these findings serve to underline the importance of taking a dynamic view, emphasising the role that each new cohort of firms plays in 'topping up' the stock of survivors of earlier cohorts, and strongly emphasize the significance of age for understanding firm survival and job growth. With many European countries struggling to encourage faster job growth this perspective has significant implications for policy design. ${ }^{29}$

\footnotetext{
29 This is a big subject and outside the scope of this paper, however it is explored in a deliberately provocative way in Shane (2009) and more recently Coad and Nightingale (2014).
} 
Table 1: Data: sources and departures from 'benchmark'

\begin{tabular}{|c|c|}
\hline Sources & \\
\hline $\begin{array}{l}\text { Austria } \\
\text { Finland } \\
\text { Germany } \\
\text { Norway } \\
\text { Sweden } \\
\text { UK }\end{array}$ & $\begin{array}{l}\text { Social Security Data } \\
\text { Statistics Finland } \\
\text { Mannheimer Unternehmenspanel (Mannheim Enterprise Panel) } \\
\text { Statistics Norway } \\
\text { Statistics Sweden } \\
\text { Office of National Statistics }\end{array}$ \\
\hline $\begin{array}{l}\text { Benchmark } \\
\text { Departures }\end{array}$ & \\
\hline $\begin{array}{l}\text { Austria } \\
\text { Finland } \\
\text { Germany } \\
\text { Norway } \\
\text { Sweden } \\
\text { UK }\end{array}$ & $\begin{array}{l}\text { NACE } 1 \text { to } 74 \\
\text { employees: full-time equivalent jobs } \\
\text { birth: "foundation"; death: "closure"; NACE } 10 \text { to } 93 \\
\text { none } \\
\text { employees: count of persons } \\
\text { none }\end{array}$ \\
\hline
\end{tabular}

Notes:

1. data for countries except Germany (see note 2 below) are compiled from official statistics. Detailed information on the sources and construction of the data will be provided by the authors on request.

2. data for Germany compiled from the Mannheimer Unternehmenspanel (MUP) dataset which currently covers nearly seven million firms, three million of which are active, with a further circa 0.7 million being categorized as insolvent and three million voluntarily closed. The data are provided biannually by the leading German credit rating agency - Creditreform. Creditreform collects information on legally independent, active firms derived from the German official register of firms, the German insolvency register, company reports, newspapers, and firm interviews. MUP has information on: identity of owners, ownership structure, location, industry classification, number of employees, sales, legal status, firm age and pathways to market exit. The panel structure of the MUP enables observing enterprises over the 1999-2012 period. 
Ptease give a shorter version with: \authorrunning and \titlerunning prior to \maketitle

Table 2: Cohorts of firms born in 1998, number of firms and job growth in Austria, Finland, Germany, Norway, Sweden \& the UK

$\begin{array}{rrr}\text { all firms } & \text { surviving firms in } 2008 & \text { ratios, rates } \\ \text { at birth } & \text { at birth } \quad \text { at end } & \text { differences }\end{array}$

(a) number of firms

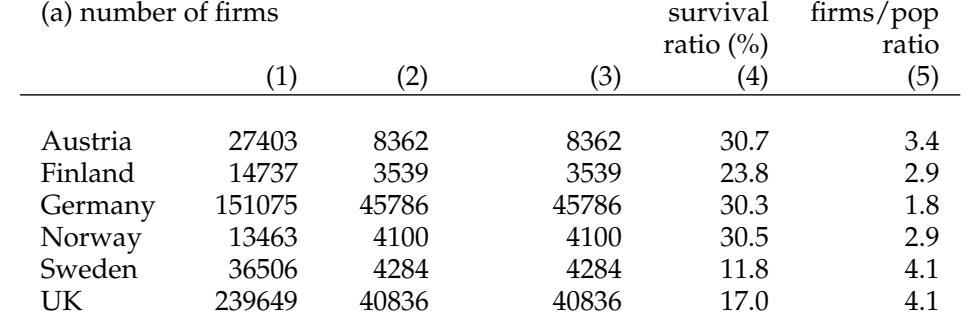

(b) number of jobs ('000)

$\begin{array}{lrrrrr} & & & (2)-(1) & (3)-(2) \\ \text { Austria } & 93.1 & 37.8 & 64.6 & -55.3 & 26.8 \\ \text { Finland } & 38.7 & 15.9 & 32.3 & -22.81 & 16.3 \\ \text { Germany } & 472.3 & 171.3 & 315.9 & -301.0 & 144.6 \\ \text { Norway } & 120.7 & 46.6 & 71.2 & -74.1 & 24.6 \\ \text { Sweden } & 259.9 & 43.6 & 58.4 & -216.3 & 14.8 \\ \text { UK } & 1123.7 & 223.6 & 460.3 & -900.1 & 236.7\end{array}$

(c) jobs per firm

\begin{tabular}{|c|c|c|c|c|c|}
\hline & & & & rat & rat \\
\hline Austria & 3.40 & 4.52 & 7.72 & 1.708 & 5.5 \\
\hline Finland & 2.62 & 4.51 & 9.12 & 2.024 & 7.3 \\
\hline Germany & 3.13 & 3.74 & 6.90 & 1.844 & 6.3 \\
\hline Norway & 8.96 & 11.37 & 17.36 & 1.527 & 4.3 \\
\hline Sweden & 7.12 & 10.19 & 13.64 & 1.339 & 3.0 \\
\hline UK & 4.69 & 5.47 & 11.27 & 2.059 & 7.5 \\
\hline Memo: & & & & & \\
\hline Norway, a & tive jc & heasure & & & \\
\hline persons & 8.24 & 10.62 & 16.07 & 1.514 & 4.3 \\
\hline FTE & 7.04 & 9.43 & 13.14 & 1.393 & 3.4 \\
\hline
\end{tabular}

Note: Birth refers to 1998 and end refers to 2008. Survival ratio is $\operatorname{col}(2) \div \operatorname{col}(1)$; firms / pop is firms per 1,000 population in 1998; growth ratio is $\operatorname{col}(3) \div \operatorname{col}(2)$; growth rate is the compound annual average rate. 


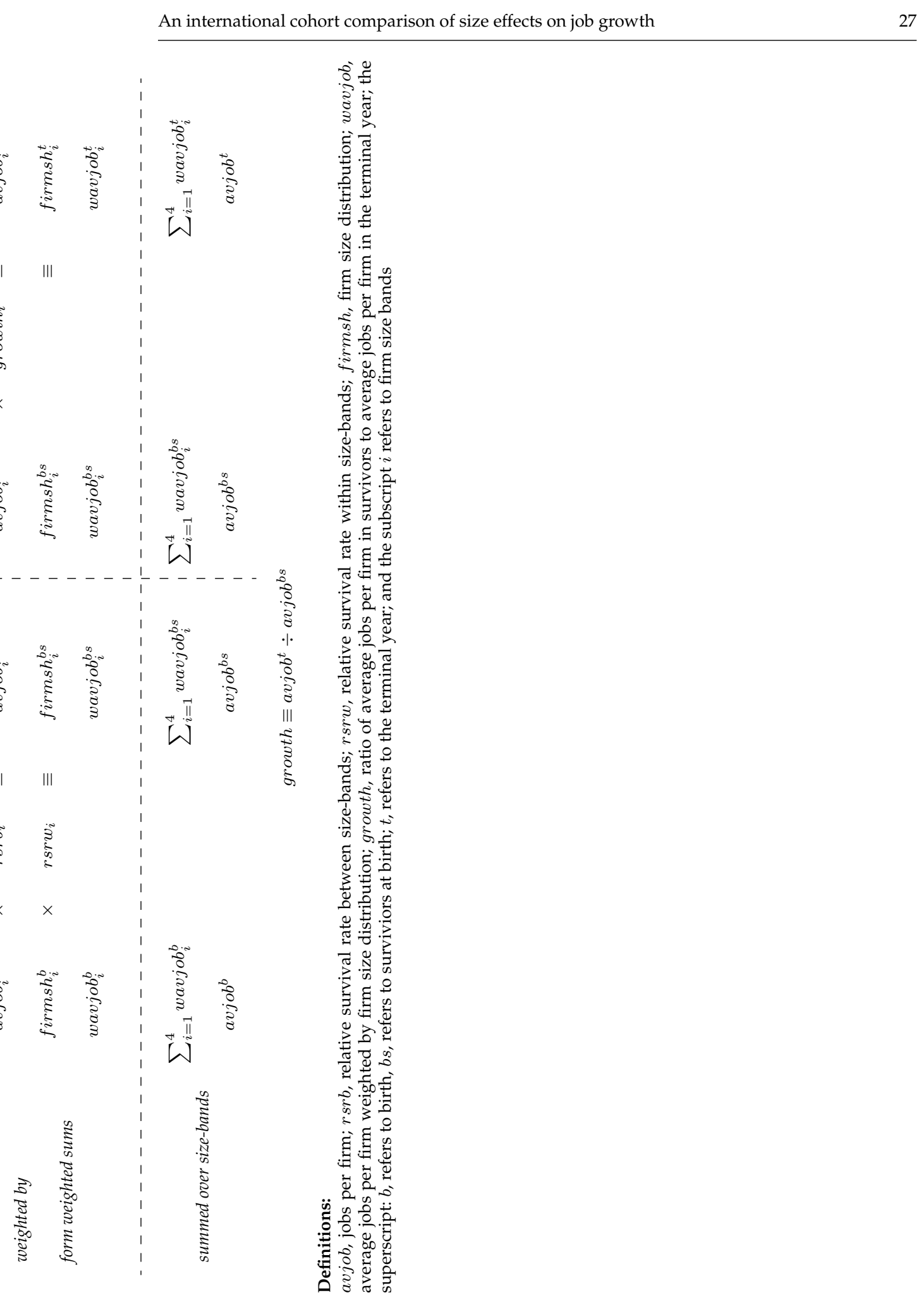


Table 4: The decomposition, Austria

\begin{tabular}{|c|c|c|c|c|c|}
\hline size-band & $\begin{array}{r}\text { birth } \\
a v j o b_{i}^{b}\end{array}$ & $\begin{array}{l}\text { survival } \\
\quad r s r w_{i}\end{array}$ & $\begin{array}{c}\text { survivors } \\
\text { avjob }_{i}^{b s}\end{array}$ & $\begin{array}{l}\text { growth } \\
\text { growth }_{i}\end{array}$ & $\begin{array}{r}\text { terminal } \\
a v j o b_{i}^{t}\end{array}$ \\
\hline $1-4$ & 1.526 & 1.125 & 1.717 & 2.340 & 4.018 \\
\hline 5-9 & 6.273 & 1.001 & 6.280 & 1.903 & 11.952 \\
\hline $10-19$ & 13.498 & 1.012 & 13.662 & 1.751 & 23.923 \\
\hline \multirow[t]{2}{*}{$20+$} & 67.573 & 0.998 & 67.417 & 1.192 & 80.361 \\
\hline & firmsh $_{i}^{b}$ & $r s r b_{i}$ & firmsh $_{i}^{b s}$ & & firmsh $_{i}^{t}$ \\
\hline $1-4$ & 0.893 & 0.945 & 0.844 & & 0.844 \\
\hline $5-9$ & 0.064 & 1.432 & 0.092 & & 0.092 \\
\hline 10-19 & 0.023 & 1.475 & 0.034 & & 0.034 \\
\hline \multirow[t]{2}{*}{$20+$} & 0.020 & 1.541 & 0.030 & & 0.030 \\
\hline & wavjob $_{i}^{b}$ & & $w a v j o b_{i}^{b s}$ & & wavjob $_{i}^{t}$ \\
\hline $1-4$ & 1.363 & & 1.449 & & 3.391 \\
\hline $5-9$ & 0.403 & & 0.577 & & 1.099 \\
\hline $10-19$ & 0.311 & & 0.464 & & 0.812 \\
\hline $20+$ & 1.322 & & 2.032 & & 2.422 \\
\hline \multirow[t]{3}{*}{ all } & $\sum_{i=1}^{4}$ wavjob $_{i}^{b}$ & & $\sum_{i=1}^{4}$ wavjob $_{i}^{b s}$ & & $\sum_{i=1}^{4}$ wavjob $_{i}^{t}$ \\
\hline & 3.398 & & 4.522 & & 7.725 \\
\hline & \multicolumn{5}{|c|}{ growth $\equiv 7.725 \div 4.522 \equiv 1.708$} \\
\hline
\end{tabular}

Definitions:

avjob, jobs per firm; $r s r b$, relative survival rate between size-bands; $r s r w$, relative survival rate within size-bands; firmsh, firm size distribution; wavjob, average jobs per firm weighted by firm size distribution; growth, ratio of average jobs per firm in survivors to average jobs per firm in the terminal year; the superscript: $b$, refers to birth, $b s$, refers to surviviors at birth; $t$, refers to the terminal year; and the subscript $i$ refers to firm size bands 
Table 5: Decomposition by country of contributions to job growth ratio birth to 2008, Austria baseline

\begin{tabular}{lrrrrrrr}
\hline & $\begin{array}{r}\text { avjob }^{b} \\
(1)\end{array}$ & $\begin{array}{r}\mathrm{fsd}^{b} \\
(2)\end{array}$ & $\begin{array}{r}\text { rsrb } \\
(3)\end{array}$ & $\begin{array}{r}\text { rsrw } \\
(4)\end{array}$ & $\begin{array}{r}\text { growth } \\
(5)\end{array}$ & $\begin{array}{r}\text { inter } \\
(6)\end{array}$ & $\begin{array}{r}\text { total } \\
(7)\end{array}$ \\
\hline UK & -0.19 & 0.05 & 0.00 & 0.04 & 0.56 & -0.10 & 0.35 \\
FI & -0.21 & 0.09 & -0.08 & 0.12 & 0.58 & -0.18 & 0.32 \\
GE & 0.20 & 0.00 & -0.01 & -0.03 & -0.12 & 0.09 & 0.14 \\
NO & -0.13 & -0.15 & -0.01 & 0.02 & 0.11 & -0.03 & -0.19 \\
SW & 0.02 & -0.18 & 0.04 & -0.09 & -0.30 & 0.14 & -0.37 \\
\hline
\end{tabular}

Key: $\operatorname{avjob}_{b}$, average number of jobs per firm at birth; $f_{s} d_{b}$, the firm size distribution at birth; rsrb , the between relative survival ratio; rsrw, the within relative survival ratio; growth, the growth ratio; inter, interaction effect; total, overall difference in growth ratio.

Note: for construction see text. 
BDease give a shorter version with: \authorrunning and \titlerunning prior to \maketitle

Table 6: Decomposition of effect of size-band specific growth ratios by country, contribution to job growth ratio, birth to 2008 , Austria baseline

\begin{tabular}{lrrrrrr}
\hline \multicolumn{7}{c}{ growth ratio by size-band } \\
& $1-4$ & $5-9$ & $10-19$ & $20+$ & inter & total \\
& $(1)$ & $(2)$ & $(3)$ & $(4)$ & $(5)$ & $(6)$ \\
\hline & & & & & & \\
UK & 0.43 & 0.04 & 0.05 & 0.05 & -0.02 & 0.55 \\
FI & 0.35 & 0.05 & 0.14 & 0.05 & -0.01 & 0.58 \\
GE & 0.18 & -0.06 & -0.05 & -0.18 & -0.01 & -0.12 \\
NO & 0.11 & 0.00 & -0.02 & 0.04 & -0.01 & 0.12 \\
SW & -0.24 & -0.05 & -0.01 & 0.02 & -0.01 & -0.29 \\
\hline
\end{tabular}

Note: This is a decomposition of the growth rate term from Table 3. Column (6) of this table corresponds to column (5) of Table 4; for construction see text. 
Table 7: Contributions of $1-4$ size-band at birth to job growth ratio by destination (2008) size-band, Austria

\begin{tabular}{lrrrr}
\hline & \multicolumn{4}{c}{ destination (2008) size-band } \\
& $\begin{array}{r}1-4 \\
(1)\end{array}$ & $\begin{array}{r}5-9 \\
(2)\end{array}$ & $\begin{array}{r}10-19 \\
(3)\end{array}$ & $\begin{array}{r}\text { 20+ } \\
(4)\end{array}$ \\
\hline & & & & \\
growth & 1.13 & 2.74 & 5.97 & 23.23 \\
selection & 0.92 & 1.33 & 1.29 & 1.32 \\
mobility & 0.800 & 0.134 & 0.044 & 0.022 \\
& & & & \\
contrib & 0.829 & 0.489 & 0.339 & 0.675 \\
share $(\%)$ & 35.6 & 21.0 & 14.5 & 28.9 \\
\hline
\end{tabular}

Memo: sum of contributions is 2.332, the growth ratio for Austrian firms born in size-band $1-4$, see Appendix ; differences due to rounding.

Note: for construction see text. 
BRease give a shorter version with: \authorrunning and \titlerunning prior to \maketitle

Table 8: Decomposition by country of contributions to $1-4$ size-band job growth ratio, birth to 2008, Austria baseline

\begin{tabular}{lrrrrr} 
& $\begin{array}{r}\text { growth } \\
(1)\end{array}$ & $\begin{array}{r}\text { select } \\
(2)\end{array}$ & $\begin{array}{r}\text { mobility } \\
(3)\end{array}$ & $\begin{array}{r}\text { inter } \\
(4)\end{array}$ & $\begin{array}{r}\text { total } \\
(5)\end{array}$ \\
\hline & & & & & \\
UK & 0.68 & -0.09 & 0.54 & 0.21 & 1.33 \\
FI & 0.59 & 0.23 & 0.25 & 0.02 & 1.10 \\
GE & 0.20 & -0.18 & 0.69 & -0.16 & 0.54 \\
NO & -0.20 & -0.12 & 0.84 & -0.19 & 0.33 \\
SW & -0.46 & -0.02 & -0.60 & 0.31 & -0.77 \\
\hline
\end{tabular}

Note: This is a calculation of the difference between Austria's 1-4 size-band growth rate decomposition from Table 6 and the other countries. Column (5) of this table is overall 1-4 growth rate for Austria less each country's 1-4 growth rate from Appendix Table 1 column (5); for construction see text. 
Fig. 1: Austria, relative survival ratios and growth ratio, by size-band, ratio (log scale)

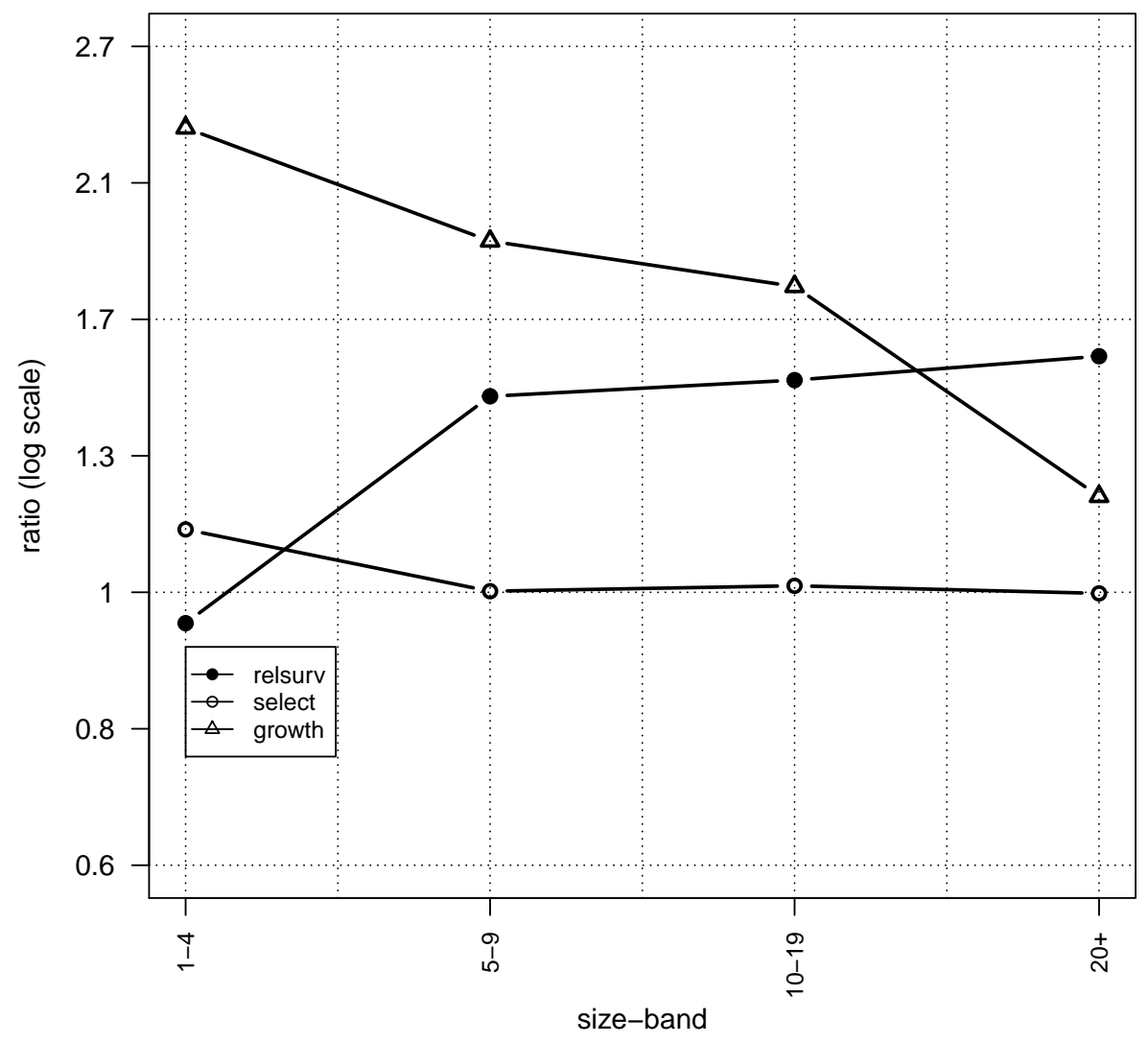

Source: Appendix Table 1, Austria, columns (3), (4) and (5).

Note: for description of the construction of the ratios see text. 
Fig. 2: growth ratios by size-band at birth, all countries, ratio (log scale)

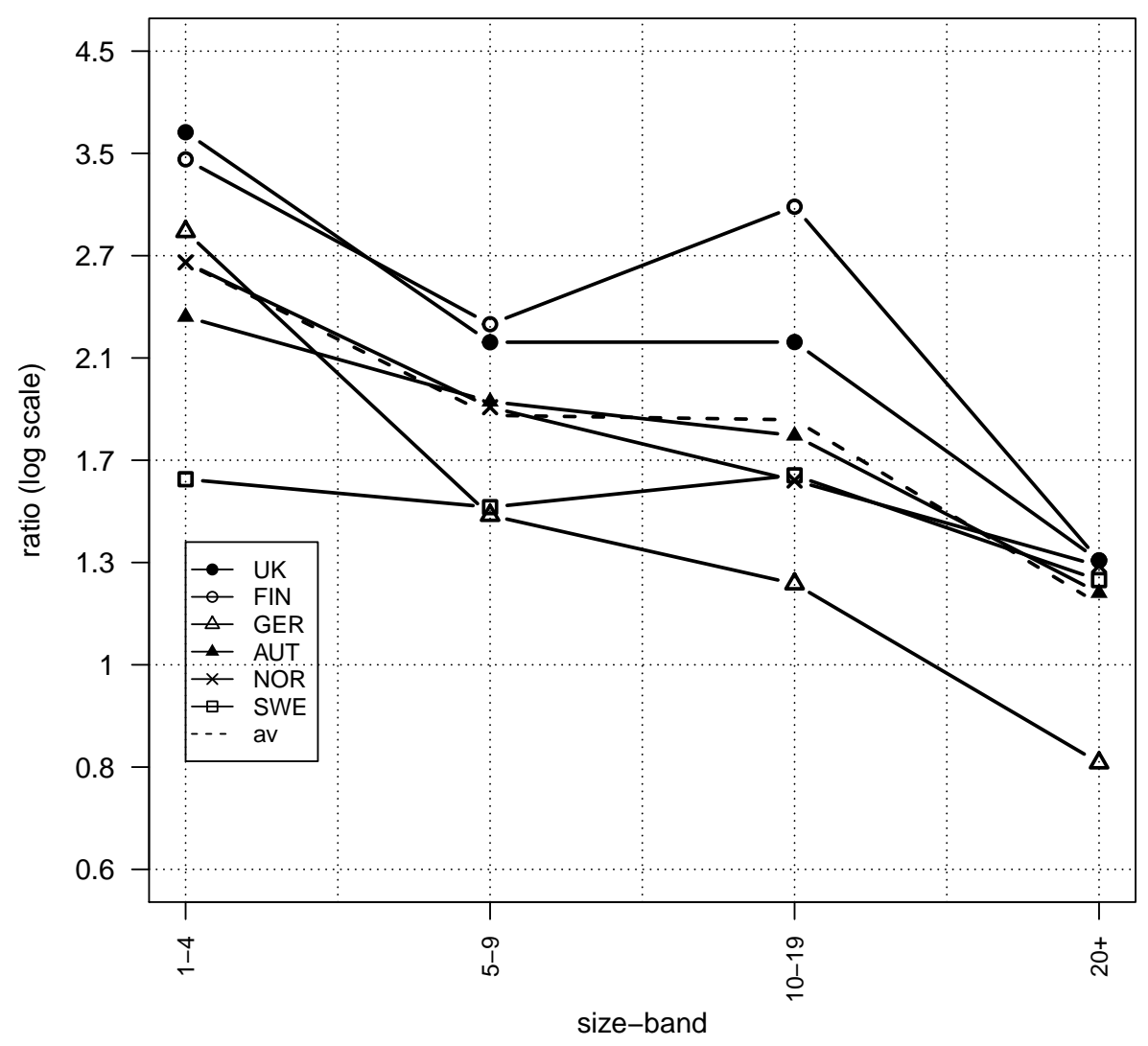

Source: Appendix Table 1, column (5); "av", average calculated. 


\section{Appendix}

\section{A.1 A framework for the decomposition of survivor job growth}

Firms at birth (in the present case 1998) are denoted by $\mathrm{firm}^{b}$, and jobs at birth by $j o b^{b}$, so average firm size (measured by jobs per firm) at birth, $a v j o b^{b}$, can be defined as,

$$
a v j o b^{b}=\frac{j o b^{b}}{f i r m^{b}}
$$

and we can denote average firm size for each of the four size-bands by $a v j o b_{i}^{b}$ where $i$ runs from 1 to 4 .

Let us also define a set of shares, $\operatorname{firmsh}_{i}^{b}$, where,

$$
\operatorname{firmsh}_{i}^{b}=\frac{\text { firm }_{i}^{b}}{\text { firm }^{b}}
$$

(and, of course, $\sum_{i=1}^{4}$ firmsh $_{i}^{b}=1$ )

We can now use the expression for shares to expand the definition of $a v j o b^{b}$,

$$
a v j o b^{b}=\sum_{i=1}^{4}\left(\operatorname{firmsh}_{i}^{b} \times a v j o b_{i}^{b}\right)
$$

Consider next the firms which survive to the 'terminal' period (in the present case 2008) $\mathrm{firm}^{\text {bs }}$. The ratio of survivors to all firms at birth is the survival rate, denoted here by $\delta$,

$$
\text { firm }^{\text {bs }}=\delta \times \text { firm }^{b}
$$

We can also define, in a parallel fashion, a survival rate $\delta_{i}$ for each size-band category and use it to re-write the definition of firmsh for the survivors,

$$
\operatorname{firmsh}_{i}^{b s}=\frac{\delta_{i} \times \text { firm }_{i}^{b}}{\delta \times \text { firm }^{b}}
$$

So we can write the average firm size for survivors at birth, $a v j o b b^{b s}$, as,

$$
\operatorname{avjob}^{b s}=\sum_{i=1}^{4}\left(\mathrm{firmsh}_{i}^{b} \times r s r b_{i} \times \operatorname{avjob}_{i}^{b s}\right)
$$

where $\frac{\delta_{i}}{\delta}$ is the between 'relative survival ratio' $\left(\operatorname{rsrb}_{i}\right)$.

The survival rate varies within size-bands as well as between size-bands, so we account for this by defining a between 'relative survival ratio' effect $\left(r s r w_{i}\right)$ - the ratio of the average size at birth of survivors in a size-band to the average size at birth of all firms in that size-band,

$$
r s r w_{i}=\frac{a v j o b_{i}^{b s}}{a v j o b_{i}^{b}}
$$

Combining these two expressions we can write,

$$
a v j o b^{b s}=\sum_{i=1}^{4}\left(f i r m s h_{i}^{b} \times r s r_{b i} \times r s r w_{i} \times a v j o b_{i}^{b}\right)
$$


Finally, if we define a growth ratio $\left(\right.$ growt $\left._{i}\right)$, expressing average firm size in the terminal period $\left(\operatorname{avjob}_{i}^{t}\right)$ as a ratio to the average size of survivors at birth,

$$
\operatorname{avjob}_{i}^{t}=\operatorname{avjob}_{i}^{b s} \times \text { growth }_{i}
$$

So we can now write,

$$
a v j o b^{t}=\sum_{i=1}^{4}\left(a v j o b_{i}^{b} \times \operatorname{firmsh}_{i}^{b} \times r s r b_{i} \times r s r w_{i} \times \text { growth }_{i}\right)
$$

by definition,

$$
\text { growth }=\frac{a v j o b^{t}}{a v j o b^{b s}}
$$

so finally,

$$
\text { growth }=\frac{\sum_{i=1}^{4}\left(\text { avjob }_{i}^{b} \times \text { firmsh }_{i}^{b} \times r s r b_{i} \times r s r w_{i} \times \text { growth }_{i}\right)}{\sum_{i=1}^{4}\left(\text { avjob }_{i}^{b} \times f \text { irmsh }_{i}^{b} \times r s r b_{i} \times r s r w_{i}\right)}
$$

and this is the expression which appears in the main text. 
A.2 The decomposition of the Austrian growth ratios

The average job/firm at birth, for survivors at birth, and survivors at age 10 can be written as the sum of weighted average jobs/firm (wavjob) overs size-bands. So the difference between birth, survivors at birth and survivors at age 10 can be written as differences in the weighted average terms. As we can see from Table 3 of the paper, the first pair of differences depend on the effect of the two relative survival rates, whilst the second pair depend only on relative growth rates.

In general,

$$
\Delta(a \times b) \equiv \Delta a \times b+\Delta b \times a+\Delta a \times \Delta b
$$

Using equation (1) we can calculate the difference - wavjob $b^{b s}$ less $w a v j o b^{b}-$ as the sum of terms (by size-band) involving: $\Delta a v j o b^{b}\left(a v j o b^{b s}\right.$ less $\left.a v j o b^{b}\right)$ and $\Delta$ firmsh $^{b}\left(\right.$ firmsh $^{b s}$ less firmsh $\left.^{b}\right)$. The results of this calculation are shown in panel (a) of the table. Similarly, we can calculate the difference - wavjob $b^{t}$ less $w a v j o b^{b s}$ - as the sum of terms (by size-band) involving: $\Delta a v j o b^{b s}\left(a v j o b^{b s}\right.$ less $\left.a v j o b^{b}\right) .{ }^{30}$ The results of this calculation are shown in panel (b) of the table.

Although the interpretation of the results in panel (a) of the table is complicated by the fact that some entries are positive and others negative, nevertheless the overall pattern seems quite clear. The effects of the 'between' survival ratio - which drives the difference in column (2) - is considerably more important than the effects of the 'within' survival ratio in column (1). Indeed, the only figure of any size in column (1) is that for the smallest size-band and, remember from Table 4 in the paper, this is the only 'within' ratio of any size). The interpretation of the results in panel (b) is more straightforward since we only have the growth terms to consider, and the finding is very clear-cut: it is the growth rate of the $1-4$ size-band which has very much the largest effect.

30 There is $\Delta$ firmsh $^{b s}$ term because, by definition, $f i r m s h^{t}$ is equal to $f i r m s h^{b s}$. 


\section{A.3 The decomposition of the size-band $1-4$ growth ratio}

The strategy here follows along similar lines, as the 'principal decomposition', using where possible the same notation. Since all the firms and jobs being referred to here originate from the 1-4 sizeband this subscript has been suppressed, and since we are now concerned only with 2008 survivors, by definition, the stock of firms at birth and in 2008 is the same, so the 'survivor' superscript (bs) is no longer necessary. However, we do need to distinguish size-bands at birth from size-bands in 2008 , these will be denoted by $b$ for birth and $t$ for 2008 .

Let us define a set of shares which record the proportions of surviving firms from size-band 1-4 in each 'destination' size-band $(i), \operatorname{mob}_{i}$, where,

$$
m o b_{i}=\frac{\text { firm }_{i}^{t}}{\text { firm }^{t}}
$$

(and, of course, $\sum_{i=1}^{4} m_{i}=1$ )

We can now use the expression for shares to expand the definition of $a v j o b^{t}$,

$$
a v j o b^{t}=\sum_{i=1}^{4}\left(m o b_{i} \times a v j o b_{i}^{t}\right)
$$

We are interested in the growth of firms, so we can divide by size at birth $\left(a v j o b^{b}\right)$,

$$
\left.\frac{a v j o b^{t}}{a v j o b^{b}}=\sum_{i=1}^{4} \frac{\left(m o b_{i} \times a v j o b_{i}^{t}\right.}{a v j o b^{b}}\right)
$$

Now expanding the denominator on the right hand side we can re-write the expression as,

$$
\frac{a v j o b^{t}}{a v j o b^{b}}=\sum_{i=1}^{4}\left(m o b_{i} \times \frac{a v j o b_{i}^{t}}{a v j o b_{i}^{b}} \times \frac{a v j o b_{i}^{b}}{a v j o b^{b}}\right)
$$

The second term on the right hand side is the ratio of avjob in 2008 to $a v j o b$ at birth for a destination size-band, so it can be interpreted as the size-band specific growth rate $g r_{i}$. The third term is the ratio of $a v j o b$ for firms in a destination size-band to the average size of 1-4 size-band firms at birth, so it is a variety of 'selection' effect, denoted sel $_{i}$. So we have,

$$
g r_{i}=\frac{a v j o b_{i}^{t}}{a v j o b_{i}^{b}}
$$

and,

$$
\operatorname{sel}_{i}=\frac{a v j o b_{i}^{b}}{a v j o b^{b}}
$$

Now re-writing the expression,

$$
\frac{a v j o b^{t}}{a v j o b^{b}}=\sum_{i=1}^{4}\left(m o b_{i} \times g r_{i} \times s e l_{i}\right)
$$

and this is the expression which appears in the main text. 
Table 9: *

Appendix Table 1: Job growth decomposition: birth to 2008, Austria, Finland, Germany, Norway, Sweden \& UK

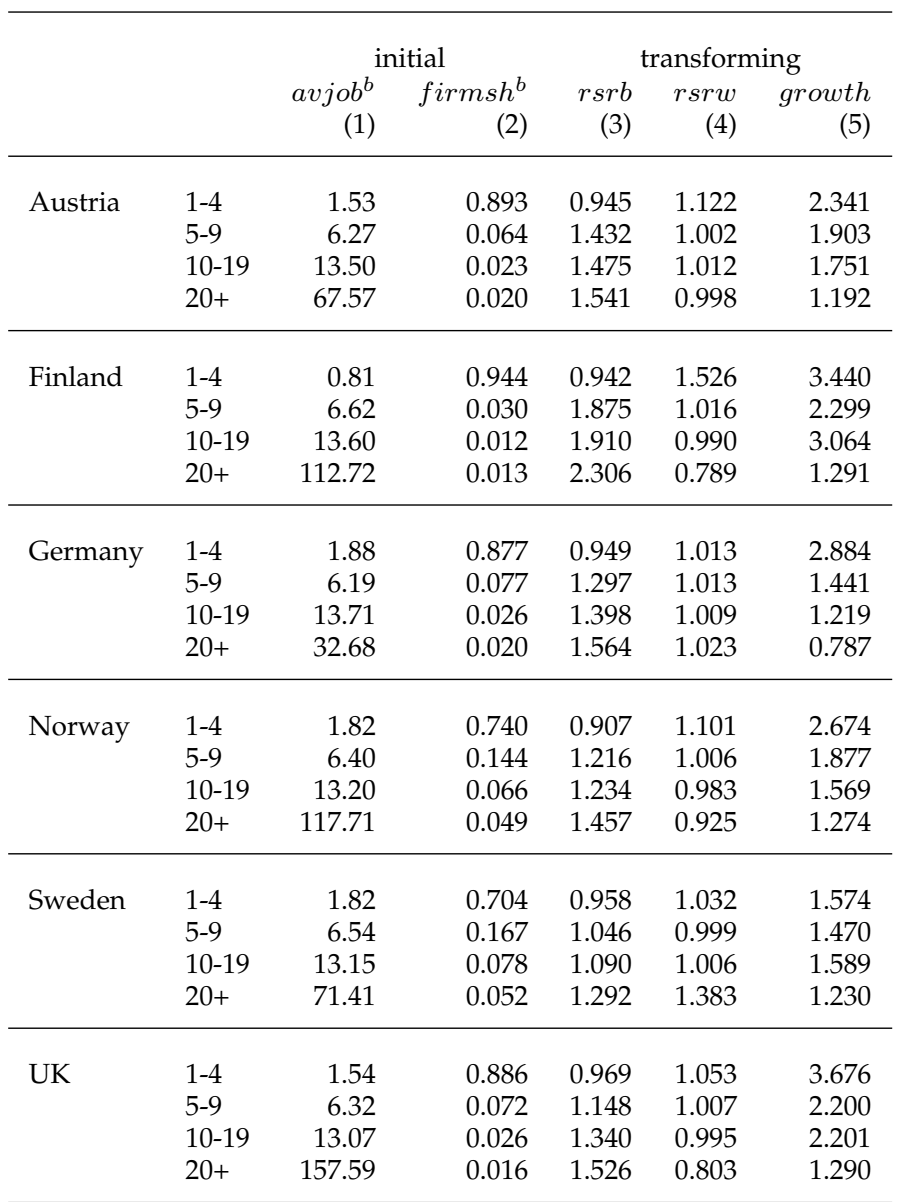

Note: for definitions and derivation of the decomposition see Appendix, A.1 
Table 10: *

Appendix Table 2: The decomposition of the Austrian growth ratios

\begin{tabular}{lrrrr}
\hline & \multicolumn{5}{c}{ (a) the effects of survival } \\
size-band & $(1)$ & $(2)$ & $(3)$ & sum \\
\hline & & & & \\
$1-4$ & 0.170 & -0.075 & -0.009 & 0.086 \\
$5-9$ & 0.000 & 0.174 & 0.000 & 0.175 \\
$10-19$ & 0.004 & 0.148 & 0.002 & 0.153 \\
$20+$ & -0.003 & 0.715 & -0.002 & 0.710 \\
all & 0.172 & 0.961 & -0.009 & 1.124 \\
\hline
\end{tabular}

(b) the effects of growth rates

\begin{tabular}{lrrrr} 
size-band & $(1)$ & $(2)$ & $(3)$ & sum \\
\hline \multirow{2}{*}{$1-4$} & 1.942 & na & na & 1.942 \\
$5-9$ & 0.522 & na & na & 0.522 \\
$10-19$ & 0.348 & na & na & 0.348 \\
$20+$ & 0.390 & na & na & 0.390 \\
& & & & \\
all & 3.203 & na & na & 3.203
\end{tabular}

Notes:

1. panel (a) columns are: (1) $\Delta a v j o b^{b} \times$ firmsh $^{b}$; (2) $\Delta$ firmsh $^{b} \times a v j o b^{b}$; (3) $\Delta a v j o b^{b} \times$ $\Delta$ firmsh $^{b}$; (4) sum of (1) to (3)

2. From Table 4 in the paper the difference between $w a v j o b^{b s}$ and $w a v j o b^{b}$ is $1.124(=4.522-3.398)$ which matches 'all' in column (4)

3. panel (b) columns are: (1) $\Delta a v j o b^{b s} \times$ firmsh $^{\text {bs }}$; col (4) $=\operatorname{col}(1)$

4. From Table 4 in the paper the difference between $w_{a v j o b}$ and $w_{a v j o b}{ }^{b s}$ is $3.203(=7.725-4.522)$

which matches 'all' in column (4) 


\section{Table 11: *}

Appendix Table 3: Austria, Finland, Germany, Norway, Sweden \& UK: contributions of $1-4$ sizeband at birth to job growth ratio by destination (2008) size-band

\begin{tabular}{llllrr}
\hline \multirow{5}{*}{ Austria } & & \multicolumn{4}{c}{ destination (2008) size-band } \\
& & $1-4$ & $5-9$ & $10-19$ & $20+$ \\
\hline \multirow{5}{*}{ Finland } & growth & 1.127 & 2.741 & 5.975 & 23.232 \\
& selection & 0.920 & 1.330 & 1.290 & 1.320 \\
& mobility & 0.800 & 0.134 & 0.044 & 0.022 \\
& growth & 1.599 & 4.030 & 6.901 & 21.920 \\
& selection & 0.880 & 1.380 & 1.540 & 1.680 \\
Germany & mobility & 0.789 & 0.130 & 0.052 & 0.029 \\
& & & & & \\
& growth & 1.233 & 3.538 & 7.433 & 19.553 \\
& selection & 0.970 & 1.080 & 1.110 & 1.150 \\
& mobility & 0.746 & 0.143 & 0.073 & 0.038 \\
& & & & & \\
Norway & growth & 1.070 & 2.791 & 5.290 & 18.749 \\
& selection & 0.920 & 1.150 & 1.240 & 1.240 \\
& mobility & 0.690 & 0.188 & 0.087 & 0.036 \\
& & & & & \\
& growth & 1.118 & 2.427 & 4.459 & 12.633 \\
Selection & 0.920 & 1.380 & 1.490 & 1.140 \\
& mobility & 0.831 & 0.134 & 0.030 & 0.005 \\
& & & & & \\
& growth & 1.252 & 3.444 & 6.583 & 37.907 \\
& selection & 0.930 & 1.170 & 1.230 & 1.280 \\
& mobility & 0.752 & 0.147 & 0.066 & 0.034 \\
\hline & & & & & \\
\hline
\end{tabular}

Note: for definitions and derivation of the decomposition see Appendix, A.2 


\section{References}

Anyadike-Danes, Michael, Karen Bonner, and Mark Hart (2012) "Exploring the incidence and spatial distribution of high growth firms in the UK and their contribution to job creation," Working Paper 13/05, NESTA.

Ayyagari, Meghana, Asli Demirguc-Kunt, and Vojislav Maksimovic (2014) "Who creates jobs in developing countries?," Small Business Economics, Vol. 43, pp. 75-99.

Bartelsman, Eric, John Haltiwanger, and Stefano Scarpetta (2004) "Microeconomic Evidence of Creative Destruction in Industrial and Developing Countries," IZA Discussion Paper 1374, IZA.

Bartelsman, Eric, John Haltiwanger, and Stefano Scarpetta (2009) "Measuring and Analysing CrossCountry Differences in Firm Dynamics," in Timothy Dunne, J. Bradford Jensen, and Mark Roberts eds. Producer Dynamics, Chicago: Chicago UP.

Bartelsman, Eric, Stefano Scarpetta, and Fabiano Schivardi (2003) "Comparative Analysis of Firm Demographics and Survival: Micro-Level Evidence for the OECD Countries," OECD Economics Department Working Papers 348, OECD Economics Department.

Bassanini, Andrea and Pascal Marianna (2009) "Looking inside the perpetual motion machine: Job and Worker Flows in OECD countries," OECD Social, Employment and Migration Working Papers 95, OECD.

Birch, David L (1979) "The Job Generation Process," research report, MIT Program on Neighborhood and Regional Change, Cambridge, MA.

Birch, David L (1987)Job Creation in America, New York: New York: Free Press.

Cabral, Luís and José Mata (2003) "On the Evolution of the Firm Size Distribution: Facts and Theory," American Economic Review, Vol. 93, No. 4, pp. 1075-1090.

Coad, Alex and Paul Nightingale (2014) " Muppets and gazelles: political and methodological biases in entrepreneurship research," Industrial and Corporate Change, Vol. 23, pp. 113-143.

Criscuolo, Chiara, Peter Gal, and Carlo Menon (2014) "The Dynamics of Employment Growth: New Evidence from 18 countries," OECD Science, Technology and Industry Policy Papers 14, OECD.

Decker, Ryan, John Haltiwanger, Ron Jarmin, and Javier Miranda (2014) "The Role of Entrepreneurship in US Job Creation and Economic Dynamism," Journal of Economic Perspectives, Vol. 28, pp. 3-24.

Dunne, Timothy, Mark Roberts, and Larry Samuelson (1989) "The growth and failure of US Manuafcturing plants," Quarterly Journal of Economics, Vol. 104, No. 4, pp. 671-698.

Ericson, Richard and Ariel Pakes (1995) "Markov-Perfect Industry Dynamics: A Framework for Empirical Work," The Review of Economic Studies, Vol. 62, No. 1, pp. pp. 53-82.

EUROSTAT-OECD (2007) EUROSTAT OECD Manual on Business Demography Statistics, Luxembourg: EUROSTAT.

Evans, David (1987) "Tests of Alternative Theories of Firm Growth," Journal of Political Economy, Vol. 95, pp. 657-674.

Haltiwanger, John (2012) "Job Creation and Firm Dynamics in the United States," in J. Lerner and S. Stern eds. Innovation Policyand the Economy, Vol. 12, Chicago: Chicago U.P.

Haltiwanger, John, Ron Jarmin, and Javier Miranda (2009) "High Growth and Failure of Young Firms," Business Dynamics Statistics Briefing 4, Kauffman Foundation.

Haltiwanger, John, Ron Jarmin, and Javier Miranda (2013) "Who creates jobs? Small vs Large vs Young," Review of Economics and Statistics, pp. 347-361.

Haltiwanger, John, Stefano Scarpetta, and Helena Schweiger (2006) "Assessing Job Flows across Countries: the Role of Industry, Firm Size and Regulations," Discussion Paper 2450, IZA.

Haltiwanger, John, Stefano Scarpetta, and Helena Schweiger (2010) "Cross country differences in job reallocation: the role of industry, firm size and regulations," EBRD Working Paper 116, EBRD.

Headd, Brian (2010) "An Analysis of Small Business and Jobs," Research Report 359, SBA Office of Advocacy.

Headd, Brian and Bruce Kirchhoff (2009) "The Growth, Decline and Survival of Small Businesses: An Exploratory Study of Life Cycles," Journal of Small Business Management, Vol. 47, pp. 531-550.

Henrekson, Magnus and Dan Johansson (2010) "Gazelles as job creators: a survey and interpretation of the evidence," Small Business Economics, Vol. 35, No. 2, pp. 227-244.

Hopenhayn, Hugo A. (1992) "Entry, Exit, and firm Dynamics in Long Run Equilibrium," Econometrica, Vol. 60, No. 5, pp. pp. 1127-1150.

Hurst, Erik and Benjamin Pugsley (2011) “What do small businesses do?," Brookings Papers in Economic Activity, Vol. Fall, pp. 73-118.

Jovanovic, Boyan (1982) "Selection and the Evolution of Industry," Econometrica, Vol. 50, No. 3, pp. pp. 649-670. 
Kirchhoff, Douglas (1994) Entrepreneurship and Dynamic Capitalism, Westport, Connecticut: Praeger. Knaup, A. and M. Piazza (2007) "Who Creates Jobs? Small versus Large versus Young," Monthly Labor Review, pp. 3-10.

Lawless, Martina (2014) "Age or size? Contributions to job creation," Small Business Economics, Vol. 42, pp. $815-830$.

Neumark, David, Brandon Wall, and Junfu Zhang (2011) "Do Small Businesses Create More Jobs? New Evidence for the United States from the National Establishment Time Series," The Review of Economics and Statistics, Vol. 93, No. 1, pp. 16-29.

Phillips, Bruce and Bruce Kirchhoff (1989) "Formation, Growth and Survival: Small Firm Dynamics in the U.S. Economy," Small Business Economics, Vol. 1, pp. 65-74.

Schreyer, Paul (2000) "High-Growth Firms and Employment," OECD Science, Technology and Industry Working Papers 2000/3, OECD Publishing.

Shane, Scott (2009) "Why encouraging more people to become entrepreneurs is bad public policy," Small Business Economics, Vol. 33, No. 2, pp. 141-149.

Stangler, Dane and Paul Kedrosky (2010) "Neutralism and Entrepreneurship: The Structural Dynamics of Startups, Young Firms and Job Creation," research series: Firm formation and economic growth, Kauffman Foundation.

Vale, Steven (2006) "The International Comparability of Business Start-up Rates: Final Report," mimeo, OECD and ONS.

van Wissen, Leo (2002) "Demography of the firm: a useful metaphor?," European Journal of Population, Vol. 18, pp. 263-279.

de Wit, Gerrit and Jan de Kok (2014) “Do small businesses creat more jobs? New evidence for Europe," Small Business Economics, Vol. 42, pp. 283-295. 